\title{
Testing hypotheses for the origin of steep slope of lunar size-frequency distribution for small craters
}

\author{
Noriyuki Namiki ${ }^{1}$ and Chikatoshi Honda ${ }^{2}$ \\ ${ }^{1}$ Department of Earth and Planetary Sciences, Kyushu University, Hakozaki 6-10-1, Higashi-ku, Fukuoka 812-8581, Japan \\ ${ }^{2}$ The Institute of Space and Astronautical Science, Yoshinodai 3-1-1, Sagamihara 229-8510, Japan
}

(Received June 13, 2001; Revised June 24, 2002; Accepted January 6, 2003)

\begin{abstract}
The crater size-frequency distribution of lunar maria is characterized by the change in slope of the population between 0.3 and $4 \mathrm{~km}$ in crater diameter. The origin of the steep segment in the distribution is not well understood. Nonetheless, craters smaller than a few $\mathrm{km}$ in diameter are widely used to estimate the crater retention age for areas so small that the number of larger craters is statistically insufficient. Future missions to the moon, which will obtain high resolution images, will provide a new, large data set of small craters. Thus it is important to review current hypotheses for their distributions before future missions are launched. We examine previous and new arguments and data bearing on the admixture of endogenic and secondary craters, horizontal heterogeneity of the substratum, and the size-frequency distribution of the primary production function. The endogenic crater and heterogeneous substratum hypotheses are seen to have little evidence in their favor, and can be eliminated. The primary production hypothesis fails to explain a wide variation of the size-frequency distribution of Apollo panoramic photographs. The secondary craters are likely the major source of the steepening of the distribution. It is ambiguous, however, which primary craters can produce sufficiently numerous secondary craters. The regional variation of the sizefrequency distributions shows that few large impacts produce enough secondary craters to affect the distributions in the surrounding area. We emphasize that a crater size-frequency distribution of small craters on the moon should not be taken as an indication of the surface age. More data obtained from future lunar missions should be viewed in this context, and continued to be examined for further insight into the possible formation mechanism for secondary craters.
\end{abstract}

\section{Introduction}

It is well known that a number density of craters increases monotonically with time on planets and satellites where volcanic resurfacing and fluid erosion are of negligible importance. Also, crater counting on planetary surfaces reveals that the number density decreases as the crater diameter increases (e.g., Basaltic Volcanism Study Project, 1981; Chapman and McKinnon, 1986; Melosh, 1989). Then, in the ideal case, the cumulative number density of craters per $\mathrm{km}^{2}, \sigma$, is described by a power-law distribution of crater diameter in km, D (Basaltic Volcanism Study Project, 1981; Melosh, 1989),

$$
\sigma(D)=\alpha D^{\beta}
$$

where $\alpha$ is a coefficient that increases with the age of surface. The index, $\beta$, is the slope of (1) in a $\log (D)$ vs. $\log (\sigma)$ plot and is usually a constant close to -2 (e.g., Melosh, 1989).

The crater size-frequency distribution on the lunar maria is a well-known exception from (1) (e.g., Basaltic Volcanism Study Project, 1981; Wilhelms et al., 1987; Melosh, 1989). An average crater size-frequency distribution over the lunar maria consists of three segments (Fig. 1). These segments are divided at diameters around 0.3 and $4 \mathrm{~km}$, and each segment has a characteristic slope. In the segment for $D$ larger

Copy right(c) The Society of Geomagnetism and Earth, Planetary and Space Sciences (SGEPSS); The Seismological Society of Japan; The Volcanological Society of Japan; The Geodetic Society of Japan; The Japanese Society for Planetary Sciences. than $4 \mathrm{~km}$, the value of $\beta$ of (1) varies in the range between -1.6 and -2.0 depending on the area, with the average of -1.8 (Wilhelms et al., 1987). Because the value of $\alpha$ of (1) in this diameter range uniquely corresponds to the radiometric age of the returned rock samples, $\alpha$ in this segment is used to determine the surface age of the lunar maria (e.g., Basaltic Volcanism Study Project, 1981). In the segment for $D$ smaller than $0.3 \mathrm{~km}$, the value of $\beta$ is again close to -2 . According to the previous studies by impact experiments and numerical simulations, the craters in this diameter range are inferred to be in equilibrium (e.g., Gault, 1970; Chapman and McKinnon, 1986; Hartmann and Gaskel, 1997). That is, the number density of craters has reached steady state, in which the formation of the new craters and the consequent erosion of old craters are in balance. In crater equilibrium, $\alpha$ in (1) does not depend on time, but is a constant between 0.015 and 0.15 (e.g., Gault, 1970; Melosh, 1989).

The segment for diameter larger than $0.3 \mathrm{~km}$ and smaller than $4 \mathrm{~km}$ is distinguished by a steep slope where the value of $\beta$ lies in the range between -3 and -4 with the average of $\beta$ of -3.4 (e.g., Melosh, 1989). Such an abrupt change in the slope (Fig. 1) has been proposed to result from either admixture of endogenic craters (Kuiper et al., 1966; Chapman et al., 1970; Schultz et al., 1976), horizontal heterogeneity of the properties of the substratum in which impact craters formed (Gault, 1970; Chapman et al., 1970, 1979; Schultz et al., 1977), a primary production function that shows a sim- 


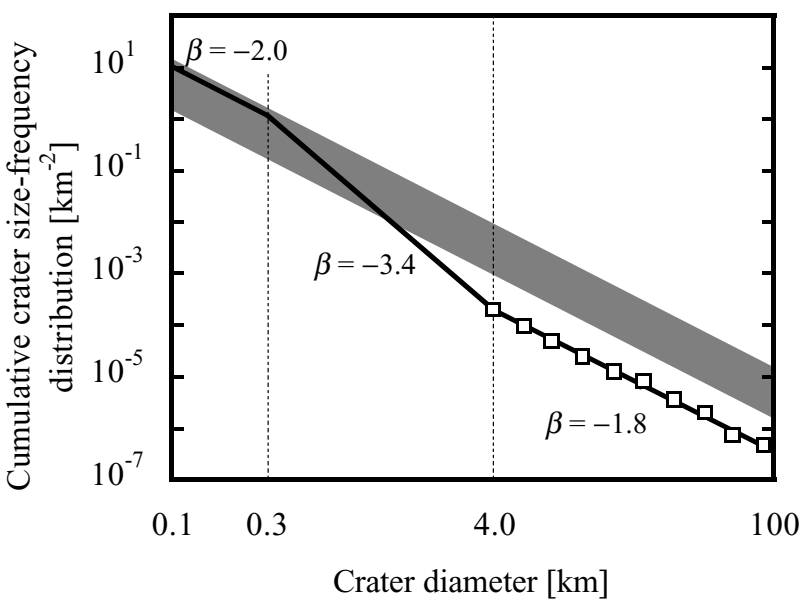

Fig. 1. A compilation of cumulative crater size-frequency distributions in lunar maria. The average cumulative crater size-frequency distribution is shown by solid line and open squares (Basaltic Volcanism Study Project, 1981, table 8.4.1; Melosh, 1989). The shaded band indicates crater equilibrium, for which $\alpha$ and $\beta$ are between 0.15 and 0.015 , and -2 , respectively (Melosh, 1989).

ilar abrupt decrease in the slope (Neukum and Wise, 1976; Neukum and Ivanov, 1994; Chapman et al., 1996), or predominance of secondary craters in the size-frequency distribution for diameters smaller than $4 \mathrm{~km}$ (Shoemaker, 1965; Wilhelms et al., 1978). Since high-resolution lunar images became available after Apollo and Lunar Orbiter spacecraft, there has been a controversy among these hypotheses (e.g., Basaltic Volcanism Study Project, 1981). While the cause of the steepening remains unsolved, small craters are widely used to estimate a surface age (e.g., Greeley et al., 1993; Neukum and Ivanov, 1994; Hartmann et al., 1999, Hartmann and Berman, 2000) on the basis of the primary production hypothesis (Neukum and Wise, 1976; Neukum and Ivanov, 1994; Chapman et al., 1996). An advantage of large number of small crater increases as images taken by the future lunar explorations, such as Japanese LUNAR-A (Mizutani, 1995) and SELENE (Sasaki et al., 1999), are expected to achieve higher resolution than previous ones. Therefore it is important to review possible hypotheses for this steepening before the new missions are launched.

These hypotheses predict that the steep slope segment is associated with a surface age or local properties of the studied area. Therefore we attempt to evaluate these hypotheses by measuring the size-frequency distributions of craters smaller than a few $\mathrm{km}$ in series of photographs covering Copernicus and Tycho craters, Oceanus Procellarum, and Mare Imbrium, and comparing the distributions with other data sets. For example, the endogenic crater hypothesis (Kuiper et al., 1966; Chapman et al., 1970; Schultz et al., 1976) implies that the steep slope segment is most distinctive on a unit such as Marius Hills where past magmatic activity is indicated from geologic studies (Weitz and Head, 1999). In contrast, on a surface younger than the cease of lunar magmatism, such as ejecta blanket of Copernican craters, the steep slope segment is not expected. Thus, measurement of the crater size-frequency distributions in young craters can be a test of this hypothesis.

The physical properties of the substrate also have been considered to influence the crater size-frequency distribution (the heterogeneous substratum hypothesis) (Gault, 1970; Chapman et al., 1970, 1979; Schultz et al., 1977). Because the crater diameter is dependent on the strength of the target in a strength regime (Chapman and McKinnon, 1986), mechanical structure of the lunar surface may affect the crater size-frequency distribution (Gault, 1970; Chapman et al., 1970, 1979). Schultz et al. (1977) further point out that properties of the target strongly affect degradation of small craters. In this case, the crater size-frequency distribution can reveal some correlation with geophysical data sets, if the data sets manifest the horizontal heterogeneity of the subsurface structure. In this context, we first investigate a correlation between the crater size-frequency distribution and thickness of mare basalt. The thickness of mare basalt is estimated to be between 0.1 and $2 \mathrm{~km}$ (DeHon and Waskom, 1976; DeHon, 1979; Yingst and Head, 1997, 1999; Budney and Lucey, 1998). A boundary at this depth may be related to the inflection of the crater size-frequency distribution around $4 \mathrm{~km}$ in diameter (Fig. 1). A shift of the inflection point to, for example, larger diameter results in an apparent increase of the $\alpha$ value. Second, we compare the crater size-frequency distributions with the topography of mare surface (Smith et al., 1997). If the topography reflects superposition of basaltic layers, a regional variation of the crater size-frequency distributions may show a correlation with the topography. And third, we compare variations of the distributions with the Bouguer gravity anomaly (Konopliv et al., 1998; Wieczorek and Phillips, 1998; Konopliv and Yuan, 1999). The gravity data represent the structure of lunar interior, therefore the horizontal heterogeneity of target properties beneath the mare surface may be somehow related to the gravity anomaly.

Neukum and Wise (1976) have proposed a third possibility that attributes the steep slope segment of the crater size-frequency distribution to the crater production function. Their primary production hypothesis is supported by a discovery of the same steep slope segment in the crater size-frequency distribution on the asteroid Gaspra (Neukum and Ivanov, 1994; Chapman et al., 1996) and in the sizefrequency distribution of Earth-crossing asteroids (Rabinowitz et al., 1994). On the other hand, the crater sizefrequency distribution on Eros shows $\beta$ greater than -2 (Veverka et al., 2001). Therefore the size-frequency distribution of primary production requires further investigation. If the crater size-frequency distribution in the lunar maria is simply indicating that of the projectile (Neukum and Wise, 1976; Neukum and Ivanov, 1994; Chapman et al., 1996), the value of $\alpha$ necessarily corresponds to the eruption age of the mare basalt. Naturally $\alpha$ in the steep-slope segment can be applied to crater chronology and would be extremely useful to estimate the age of so small an area that only a few craters larger than $4 \mathrm{~km}$ exist (Greeley et al., 1993; Hartmann et al., 1999; Hartmann and Berman, 2000). We wish to test this hypothesis from a comparison of radiometric ages with the $\alpha$ values of the steep slope segment. However, the sample locations are restricted to the Apollo and Luna landing sites, and current rock samples cover only a limited portion of the maria. Instead, we take geological maps (Pieters, 1978; Whitford-Stark and Head, 1980; Wilhelms et al., 1987) un- 
Table 1. Summary of location, geologic classification, least-squares fits, and $\chi^{2}$ test for all photographs taken in this study (Pieters, 1978; Whitford-Stark and Head, 1980; Wilhelms et al., 1987).

\begin{tabular}{|c|c|c|c|c|c|c|c|c|c|c|}
\hline Group & $\begin{array}{l}\text { Photograph } \\
\text { Number }\end{array}$ & $\begin{array}{l}\text { Latitude, } \\
{ }^{\circ} \mathrm{N}\end{array}$ & $\begin{array}{l}\text { Longitude, } \\
{ }^{\circ} \mathrm{W}\end{array}$ & $\begin{array}{c}\text { Pieters } \\
(1978) \S\end{array}$ & $\begin{array}{c}\text { Classifications } \\
\text { Whitford-Stark } \\
\text { and Head (1980)\# }\end{array}$ & $\begin{array}{l}\text { Wilhelms } \\
\text { et al. }(1987)^{*}\end{array}$ & $\alpha, \mathrm{x} 10^{-3}$ & $\alpha$ & $Q$ & $\begin{array}{l}\text { Diameter range, } \\
\text { km }\end{array}$ \\
\hline \multirow{3}{*}{$\begin{array}{l}\text { Lunar } \\
\text { Orbiter }\end{array}$} & LO5H127 & -41.0 & 13.0 & & & Co 0 & $0.0068 \pm 0.0045$ & $-4.39 \pm 0.30$ & 0.750 & $0.08-0.30$ \\
\hline & LO5H153 & 10.0 & 20.0 & & & $\mathrm{Co}$ & $2.42 \pm 0.24$ & $-3.30 \pm 0.12$ & 0.710 & $0.114-0.559$ \\
\hline & LO4H121 & 10.0 & 15.0 & & & $\mathrm{Co}$ & $0.89 \pm 0.08$ & $-3.64 \pm 0.26$ & 0.790 & $0.921-2.57$ \\
\hline \multirow{12}{*}{ Metric 1} & AS $15-2056$ & 26.1 & 9.6 & & & & $7.76 \pm 0.18$ & $-3.02 \pm 0.04$ & 0.855 & $1.06-2.92$ \\
\hline & AS $15-2060$ & 27.0 & 15.3 & & & & $6.91 \pm 0.64$ & $-4.42 \pm 0.20$ & 0.514 & $1.05-2.90$ \\
\hline & AS $15-2064$ & 27.8 & 20.5 & & & & $4.27 \pm 0.39$ & $-3.28 \pm 0.18$ & 0.423 & $0.75-2.91$ \\
\hline & AS $15-2068$ & 28.3 & 25.7 & & & & $4.37 \pm 0.20$ & $-3.36 \pm 0.04$ & 0.997 & $1.47-5.80$ \\
\hline & AS $15-2072$ & 28.6 & 31.3 & & & & $3.16 \pm 0.07$ & $-4.09 \pm 0.12$ & 0.575 & $0.74-2.06$ \\
\hline & AS $15-2076$ & 28.8 & 36.6 & & & & $5.25 \pm 0.24$ & $-3.49 \pm 0.11$ & 0.539 & $0.75-2.95$ \\
\hline & AS $15-2080$ & 28.6 & 42.1 & & & & $7.08 \pm 0.16$ & $-3.29 \pm 0.05$ & 0.832 & $1.03-2.89$ \\
\hline & AS $15-2480$ & 28.8 & 48.0 & & & & $7.59 \pm 1.23$ & $(-2.69 \pm 0.22)$ & 0.598 & $1.42-3.98$ \\
\hline & AS $15-2484$ & 28.7 & 54.0 & & & & $2.95 \pm 0.20$ & $-3.23 \pm 0.21$ & 0.454 & $0.71-1.99$ \\
\hline & AS $15-2746$ & 28.4 & 59.7 & & & & $3.39 \pm 0.63$ & $-3.07 \pm 0.64$ & $(0.007)$ & $0.71-2.00$ \\
\hline & AS $15-2748$ & 27.7 & 65.5 & & & & $3.24 \pm 0.03$ & $-3.37 \pm 0.03$ & 0.905 & $0.72-2.02$ \\
\hline & AS $15-2490$ & 27.7 & 62.7 & & & & $3.31 \pm 0.03$ & $(-2.90 \pm 0.03)$ & 0.889 & $0.70-1.99$ \\
\hline \multirow{4}{*}{ Metric 2} & AS $15-1838$ & 25.7 & 22.8 & & & & $3.31 \pm 0.03$ & $(-2.93 \pm 0.05)$ & 0.865 & $1.01-2.83$ \\
\hline & AS $15-1842$ & 25.6 & 28.2 & & & & $8.71 \pm 4.38$ & $-3.91 \pm 0.43$ & 0.642 & $2.05-5.79$ \\
\hline & AS $15-1846$ & 25.3 & 33.7 & & & & $5.25 \pm 0.73$ & $-3.72 \pm 0.32$ & 0.295 & $1.02-2.89$ \\
\hline & AS $15-1850$ & 24.9 & 39.1 & & & & $6.03 \pm 1.12$ & $-3.86 \pm 0.42$ & 0.231 & $1.02-2.89$ \\
\hline \multirow{29}{*}{ Panoramic } & AS $15-0260$ & 26.6 & 23.5 & hDSA & & $\mathrm{Er}$ & $1.58 \pm 0.01$ & $-4.25 \pm 0.02$ & 0.997 & $0.383-1.41$ \\
\hline & AS $15-0264$ & 26.9 & 24.9 & LBSP & & $\mathrm{Im}$ & $0.525 \pm 0.13$ & $-4.76 \pm 0.25$ & 0.452 & $0.272-0.690$ \\
\hline & AS $15-0268$ & 27.1 & 26.3 & hDSA & & Er & $1.82 \pm 0.34$ & $-4.03 \pm 0.18$ & 0.494 & $0.278-0.711$ \\
\hline & AS $15-0272$ & 27.3 & 27.3 & hDSA & & $\mathrm{Er}$ & $2.40 \pm 0.11$ & $-3.61 \pm 0.03$ & 0.909 & $0.207-0.708$ \\
\hline & AS $15-0276$ & 27.5 & 29.3 & hDSA & & Er & $1.82 \pm 0.17$ & $-3.89 \pm 0.13$ & 0.967 & $0.284-1.44$ \\
\hline & AS $15-0280$ & 27.7 & 30.7 & $\mathrm{hDSA}$ & & Er & $3.80 \pm 0.62$ & $-3.55 \pm 0.14$ & 0.456 & $0.217-0.758$ \\
\hline & AS $15-0284$ & 27.9 & 32.2 & LBSP & & $\operatorname{Im}$ & $9.77 \pm 0.23$ & $-3.29 \pm 0.02$ & 0.956 & $0.387-1.03$ \\
\hline & AS $15-0288$ & 28.1 & 33.6 & LBSP & Sharp & $\operatorname{Im}$ & $1.82 \pm 0.25$ & $-3.95 \pm 0.25$ & 0.792 & $0.385-1.43$ \\
\hline & AS $15-0292$ & 28.2 & 35.0 & LBSP & Sharp-Hermann & Im & $2.14 \pm 0.97$ & $-5.05 \pm 1.07$ & 0.103 & $0.533-1.46$ \\
\hline & AS $15-0296$ & 28.3 & 36.5 & LBSP & Hermann & $\mathrm{Im}$ & $9.12 \pm 0.21$ & $-3.05 \pm 0.05$ & 0.991 & $0.526-2.02$ \\
\hline & AS $15-0300$ & 28.5 & 37.9 & hDSA & Sharp-Hermann & $\mathrm{Er}$ & $4.68 \pm 0.98$ & $-4.16 \pm 0.52$ & 0.365 & $0.539-1.48$ \\
\hline & AS $15-0304$ & 28.5 & 39.5 & LBSP & Sharp-Hermann & $\operatorname{Im}$ & $3.89 \pm 0.36$ & $-4.22 \pm 0.12$ & 0.680 & $0.373-1.00$ \\
\hline & AS $15-0308$ & 28.6 & 41.0 & LBSP & Telemann & $\mathrm{Im}$ & $1.26 \pm 0.12$ & $-4.77 \pm 0.13$ & 0.750 & $0.367-0.988$ \\
\hline & AS $15-0312$ & 28.7 & 42.3 & LBSP & Telemann & $\operatorname{Im}$ & $5.37 \pm 0.37$ & $-4.08 \pm 0.13$ & 0.945 & $0.362-1.94$ \\
\hline & AS $15-0316$ & 28.8 & 43.7 & LBSP & Telemann & $\operatorname{Im}$ & $5.75 \pm 0.13$ & $-3.90 \pm 0.11$ & 0.905 & $0.702-1.95$ \\
\hline & AS $15-0320$ & 28.8 & 45.2 & LBG- & Telemann & $\operatorname{Im}$ & $5.75 \pm 0.27$ & $-3.17 \pm 0.05$ & 0.972 & $0.347-1.32$ \\
\hline & AS $15-0324$ & 28.8 & 46.7 & LBG- & Telemann & $\operatorname{Im}$ & $2.00 \pm 0.09$ & $-4.86 \pm 0.07$ & 0.794 & $0.365-0.995$ \\
\hline & AS $15-0328$ & 28.8 & 48.3 & LBG- & Telemann & $\mathrm{Im}$ & $33.11 \pm 5.36$ & $-3.20 \pm 0.27$ & 0.880 & $0.960-3.78$ \\
\hline & AS $15-0332$ & 28.8 & 49.4 & LBG- & Telemann & $\operatorname{Im}$ & $8.32 \pm 0.58$ & $-3.33 \pm 0.15$ & 0.745 & $0.481-1.32$ \\
\hline & AS $15-0344$ & 28.6 & 53.6 & Undivided & Telemann & Er & $4.27 \pm 0.20$ & $-3.37 \pm 0.12$ & 0.895 & $0.472-1.84$ \\
\hline & AS $15-0348$ & 28.6 & 54.9 & HDSA & Telemann & $\mathrm{Er}$ & $9.77 \pm 0.23$ & $-3.12 \pm 0.03$ & 0.956 & $0.556-1.54$ \\
\hline & AS $15-0352$ & 28.5 & 56.3 & HDSA & Sharp & Co & $1.00 \pm 0.01$ & $-4.22 \pm 0.01$ & 0.951 & $0.257-0.705$ \\
\hline & AS $15-0356$ & 28.4 & 57.7 & HDSA & Sharp & Co & $2.69 \pm 0.25$ & $-3.61 \pm 0.07$ & 0.583 & $0.181-0.493$ \\
\hline & AS $15-0358$ & 28.3 & 58.4 & HDSA & Sharp & $\mathrm{Co}$ & $2.75 \pm 0.64$ & $-3.75 \pm 0.30$ & 0.712 & $0.354-0.983$ \\
\hline & AS $15-0360$ & 28.3 & 59.1 & HDSA & Sharp & $\mathrm{Co}$ & $4.57 \pm 0.53$ & $-3.31 \pm 0.13$ & 0.430 & $0.222-1.21$ \\
\hline & AS $15-0362$ & 28.1 & 60.4 & hDSA & Sharp & $\mathrm{Co}$ & $3.47 \pm 0.08$ & $-3.58 \pm 0.05$ & 0.934 & $0.434-1.21$ \\
\hline & AS $15-0364$ & 28.0 & 62.0 & hDSA & Sharp & $\mathrm{Co}$ & $2.04 \pm 0.09$ & $-4.19 \pm 0.07$ & 0.899 & $0.302-1.19$ \\
\hline & AS $15-0366$ & 27.8 & 63.4 & hDSA & Sharp & $\mathrm{Er}$ & $11.5 \pm 0.11$ & $-3.13 \pm 0.01$ & 0.950 & $0.221-0.616$ \\
\hline & AS $15-0370$ & 27.4 & 66.3 & mISP & Hermann & $\mathrm{Im}$ & $2.00 \pm 0.23$ & $-4.66 \pm 0.20$ & 0.712 & $0.428-1.20$ \\
\hline
\end{tabular}

Note: Photographs grouped as metric 1 and 2 are taken from different tracks of Apollo 15 (Fig. 2). The average latitude of metric 1 and 2 groups are $28.0^{\circ} \mathrm{N}$ and $25.4^{\circ} \mathrm{N}$, respectively. $\S$ : Classification is based on spectral map compiled by Wilhelms et al. (1987, pl. 4) from Pieters et al. (1975), Head et al. (1978), and Pieters (1978). The region adopted in this work has been studied by Pieters (1978). First letter H-h-m-L indicates range of UV/VIS ratios from $\mathrm{H}$ (high) to L (low), respectively. Second letter B-I-D indicates albedo, from Bright (B) to dark (D), respectively. Third letter S-G indicates nature of the mafic mineral absorption band near $1 \mathrm{~mm}$, strong $(\mathrm{S})$ and gentle $(\mathrm{G})$, respectively. Forth letter P-A indicates nature of the pyroxene absorption band near $2 \mathrm{~mm}$, prominent (P) and attenuated (A). \#: Geologic units are classified by surface age (Whitford-Stark and Head, 1980). The Sharp formation consists of the youngest units, and the Telemann formation consist of the oldest units. Sharp + Hermann indicates that the panoramic picture lies on the boundary between the two formations. *: Classification is taken from surface age determined by Wilhelms et al. (1987, pl. 12). Im, Er, and Co denote Imbrian, Eratosthenian, and Copernican, respectively.

der the assumption that each geological unit represents concurrent eruptions.

As for the secondary crater hypothesis (Shoemaker, 1965; Wilhelms et al., 1978), there are two different interpretations depending on the size of the primary crater. First, if all primary craters are accompanied by small secondary craters, this interpretation is indistinguishable from the primary production hypothesis (Basaltic Volcanism Study Project, 1981). There is then no need for a new test. Second, if only primary craters larger than a few tens $\mathrm{km}$ in diameter can produce secondary craters (Shoemaker, 1965), the number density of the secondary craters would decrease with distance from a local large crater. Thus, we can test this hypothesis by examining a variation of the $\alpha$ value of the steep slope segment depending on the distance from large primary craters.

\section{Data Sets and Handling}

\subsection{Geological settings and photographs of the studied area}

We examine the crater size-frequency distributions of Copernicus and Tycho craters first. Copernicus crater lies 


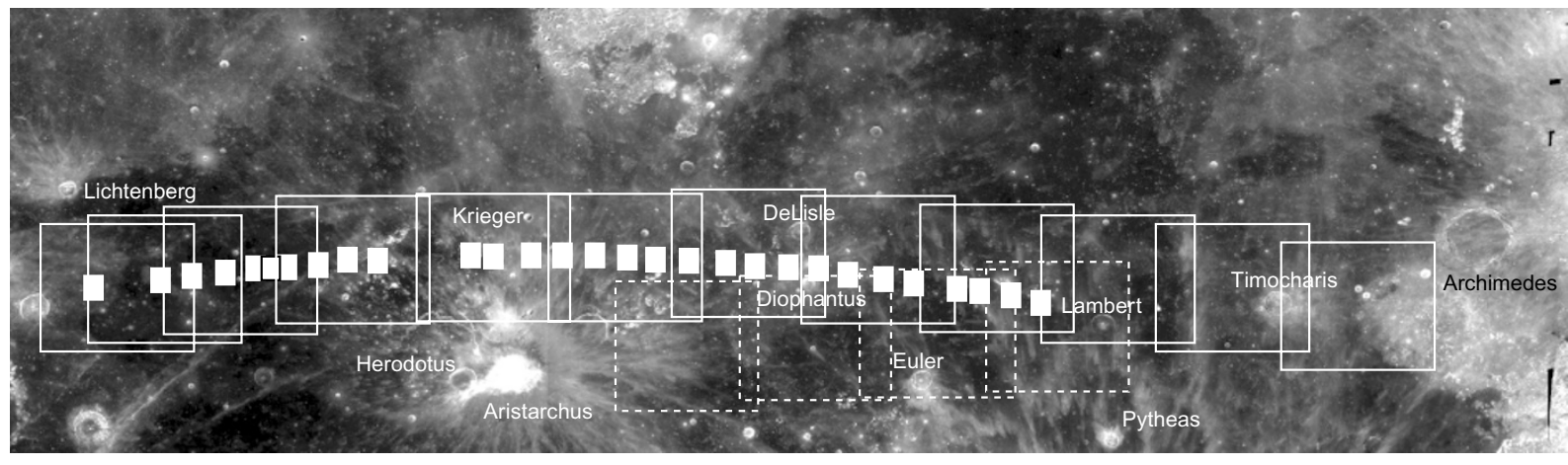

Fig. 2. A mosaic of Clementine UV/VIS images from $0^{\circ} \mathrm{W}$ to $70^{\circ} \mathrm{W}$ and from $20^{\circ} \mathrm{N}$ to $40^{\circ} \mathrm{N}$. The area covered by the panoramic, metric 1 , and metric 2 photographs (Table 1) are superimposed by small solid rectangles, large open rectangles, and large dashed rectangles, respectively.

at $10^{\circ} \mathrm{N}$ and $20^{\circ} \mathrm{W}$ on the southernmost part of Mare Imbrium. Its age is estimated to be about 0.81 b.y. from U-Th$\mathrm{Pb}$ and $\mathrm{K}-\mathrm{Ar}$ dating of regolith sample and a degassing event in KREEP glass collected at the Apollo 12 site (e.g., Silver, 1971; Alexander et al., 1976, 1977; Bogard et al., 1992). Tycho crater lies on the highland at $43^{\circ} \mathrm{S}$ and $11^{\circ} \mathrm{W}$. Its age is estimated to be about 0.109 b.y. from a peak in Apollo 17 soil cosmic ray exposure ages (e.g., Drozd et al., 1974; Wolfe et al., 1975; Lucchitta, 1977). We adopt three highresolution images taken by Lunar Orbiters 4 and 5 (Table 1). The LO5H127, LO5H153, and LO4H121 are photographs of the ejecta blanket of Tycho crater, and the ejecta blanket and floor of Copernicus crater, respectively. The maximum resolutions of these images are about $60 \mathrm{~m}, 2 \mathrm{~m}$, and $2 \mathrm{~m}$, respectively (Wilhelms et al., 1987).

We also investigate the crater size-frequency distributions in parts of Oceanus Procellarum and Mare Imbrium (Fig. 2). Oceanus Procellarum and Mare Imbrium are interpreted to be covered by basaltic volcanism that occurred between 3.10 and 3.25 and between 3.20 and 3.35 b.y. ago, respectively, from the radiometric ages of the rock samples returned by Apollo 12 and 15 (Basaltic Volcanism Study Project, 1981). While Wilhelms et al. (1987) claim that eruptions occurred in the Imbrian, Eratosthenian, and even Copernican systems, their age estimates are possibly subject to the population of craters in the diameter range discussed in this work. There are several craters larger than $25 \mathrm{~km}$ in diameter in this region (Fig. 2). Among these craters, Aristarchus $\left(23.7^{\circ} \mathrm{N}\right.$ and $\left.47.4^{\circ} \mathrm{W}, D=40 \mathrm{~km}\right)$, Timocharis $\left(26.7^{\circ} \mathrm{N}\right.$ and $13.1^{\circ} \mathrm{W}$, $D=34 \mathrm{~km})$, and Euler $\left(23.3^{\circ} \mathrm{N}\right.$ and $29.2^{\circ} \mathrm{W}, D=28$ $\mathrm{km})$ craters belong to the Copernican system and DeLisle $\left(29.9^{\circ} \mathrm{N}\right.$ and $\left.34.6^{\circ} \mathrm{W}, D=25 \mathrm{~km}\right)$ and Lambert $\left(5.8^{\circ} \mathrm{N}\right.$ and $21.0^{\circ} \mathrm{W}, D=30 \mathrm{~km}$ ) craters belong to the Eratosthenian system (Taylor, 1982; McEwen et al., 1997). We adopt a series of Apollo 15 metric photographs as well as panoramic photographs (Table 1) covering the region between $26^{\circ} \mathrm{N}$ and $32^{\circ} \mathrm{N}$, and between $6^{\circ} \mathrm{W}$ and $69^{\circ} \mathrm{W}$ (Fig. 2). As listed in Table 1, those metric photographs cover a wider area than panoramic photographs (Fig. 2). The maximum resolutions of metric and panoramic photographs are $20 \mathrm{~m}$ and $2 \mathrm{~m}$, respectively (Wilhelms et al., 1987).

\subsection{Corrections of Apollo 15 metric and panoramic photographs}

The metric and panoramic photographs were taken along tracks of the Apollo 15 orbiter. As a consequence, a sun elevation gradually changes from a few to 40 degrees. A correction for different solar angle has been made such that crater diameter increases from a measurement by $1 \mathrm{~m}$ per degree as sun elevation increases (Young, 1975, 1977).

Next we have made a small correction for the scale of printed photographs. Original sizes of the Apollo 15 metric and panoramic photographs are 5 by 5 and 5 by 48 inches, respectively. We have requested National Space Science Data Center to enlarge both metric and panoramic photographs by 2 and 3.2 times, respectively, so as to count small craters. At the same time, we extract only the central region ( 5 by 6.25 inches) from the original panoramic photograph because the image is highly distorted far from the center of the photograph. In order to account for differences of enlargement of each photograph, we have first measured in metric photographs the diameter of the crater that has been already catalogued by Wilhelms et al. (1987). While some metric photographs lack the catalogued craters, all metric photographs overlap each other (Fig. 2). Then the scales of those metric photographs have been interpolated from the overlaps with the adjacent photographs. Second, we have determined the scales of the panoramic photographs from those of metric photographs by taking advantage of the fact that all panoramic photographs are overlapped by metric photographs (Fig. 2). Finally, as an additional test, the lengths of letters "APOLLO" printed on the rim of the panoramic photographs are measured when they are found. Without the adjustment described above, the average and standard deviation of the length of the letters are 139 and $5 \mathrm{~mm}$, respectively. Therefore the ambiguity in scale due to enlargement is less than $4 \%$.

\subsection{Other data sets}

We adopt three geophysical data sets for tests of the endogenic processes and heterogeneous substratum hypotheses. For thickness of mare basalt, we take estimates by DeHon (1979). Although new estimates of basalt thickness for Humorum, Orientale, Smithii, and Maginis basins, and lava ponds in South Pole-Aitken basin have been ob- 
tained from the detailed analyses of Clementine multispectral images (Yingst and Head, 1997, 1999; Budney and Lucey, 1998), basalt thickness estimates for Oceanus Procellarum and Mare Imbrium have not been revised since DeHon (1979). For topography model, we adopt a set of spherical harmonic coefficients (GLTM-2) calculated from the topographic data obtained by Clementine lidar experiment (Smith et al., 1997). And for Bouguer gravity anomaly model of the Moon, we adopt the harmonic coefficients JGL100J1 (Konopliv et al., 1998; Wieczorek and Phillips, 1998; Konopliv and Yuan, 1999). This gravity model is calculated from radio tracking of the Lunar Orbiters 1 to 5, Apollo 15 and 16, Clementine, and Lunar Prospector spacecraft. The reference geoid is set to be a sphere of radius of $1738 \mathrm{~km}$, and crustal and mean densities are assumed to be 2800 and $3340 \mathrm{~kg} \mathrm{~m}^{-3}$, respectively. Magnetic anomaly data are another possible source to constrain subsurface structures. However, because Halekas et al. (2001) find no clear association between geologic features and magnetic anomalies in Lunar Prospector electron reflectometer measurements, we do not include a magnetic anomaly map in this study.

As a reference of regional geology, we adopt geologic and spectral maps of the moon by Pieters (1978), WhitfordStark and Head (1980), and Wilhelms et al. (1987) (Table 1). For some provinces, elemental and mineralogical maps have been already revised on the basis of multispectral analyses of Clementine UVVIS images (e.g., Yingst and Head, 1999; Gillis and Spudis, 2000; Hiesinger et al., 2000a, b; Pieters et al., 2001; Staid and Pieters, 2001) and Lunar Prospector $\gamma$ ray and neutron spectrometer data (Elphic et al., 1998; Feldman et al., 1998a, b; Lawrence et al., 1998). However, we do not adopt these newer maps for two reasons. First, many of these maps are not classified into geologic units. Second, when geologic units are interpreted, the crater density has been already taken into account in the classification. Thus these newer maps are neither applicable to nor independent from our tests.

\section{Results}

\subsection{Examination of statistical procedures}

The result of crater count in each size bin is listed for all photographs in Table 2, and examples of the crater sizefrequency distributions are shown in Figs. 3, 4, 5, and 6. In these figures, formal errors are calculated as a square root of the cumulative number of craters in each size bin. In practice, however, it is possible that the bias of an individual researcher is greater than the statistical deviation (Basaltic Volcanism Study Project, 1981). We compare our results with previous works (Neukum and König, 1976; Guinness and Arvidson, 1977; Young, 1977) to evaluate the bias in our counts. In Figs. 3, 4, and 5, the results by Guinness and Arvidson (1977) and Young (1977) are shown for comparison. While the differences of crater counts among the different workers are not negligible, the number densities agree each other in general. Two exceptions are the crater size-frequency distributions in a diameter range greater than $100 \mathrm{~m}$ in Fig. 3, and that of the Copernicus floor by Young (1977) in Figs. 4(a) and (b). A comparison with the results by Neukum and König (1976) is made only graphically because the numbers of craters counted by Neukum and
König (1976) are not available in the literature. Their crater counts on Copernicus floor and ejecta blanket are consistent with others while that on Tycho is markedly different. The cause of occasional differences among these databases is not clear. However, the general agreement supports the use of our crater counts.

We find the best-fit parameters of (1) for each photograph paying attention to the left/right-hand effect (Pickering et al., 1995) and the goodness-of-fit. First, no crater smaller than $1 \mathrm{~mm}$ in diameter on Apollo metric and Lunar Orbiter photographs is taken into account in our statistics. We set this criterion as a conservative lower bound through preliminary tests. For panoramic photographs, we have started with the crater counts of AS15-0260 (Table 1). Then we have confirmed that craters smaller than $2.8 \mathrm{~mm}$ in diameter on the photograph $(D=0.13 \sim 0.18 \mathrm{~km}$ on the moon) are in the crater equilibrium (e.g., Gault, 1970; Chapman and McKinnon, 1986; Hartmann and Gaskel, 1997) (Table 2 and Fig. 6). Therefore the craters smaller than this diameter are not taken into account in the later counts of Apollo panoramic photographs (Table 1). Although the craters at this diameter are not in the equilibrium in some photographs, our estimates of $\alpha$ and $\beta$ (Table 1) are little dependent on this lower bound of the diameter range (Table 2 ).

Second, in order to determine the diameter range of the steep slope segment in a statistical manner, we apply the $\chi^{2}$ test (Press et al., 1988) to our crater counts. We calculate $\alpha$ and $\beta$ for least-squares fit on cumulative plot, and then evaluate the goodness-of-fit, $Q$, for all diameter ranges to find a maximum value of $Q$ for each photograph. In Table 1, the $\alpha$ and $\beta$, the maximum value of $Q$, and the adopted range of diameter are summarized for each photograph. Among 48 photographs, the crater size-frequency distributions of three metric photographs reveal $\beta$ greater than -3 (AS152480,2490 , and 1838). Because an obvious signature of the steep slope segment is absent, these photographs are excluded from the following discussions. In addition, the metric photograph AS15-2746 is also excluded, because the maximum $Q$ value is smaller than 0.1 . The least-squares fit of this photograph is not statistically reliable (Press et al., 1988).

The variation of $\alpha$ in Oceanus Procellarum and Mare Imbrium is shown in Fig. 7. It is clear in this figure that $\alpha$ values of the panoramic photographs show regional variations as large as a factor of 10 . Such large variations cannot be explained by statistical deviations. In contrast, variations of $\alpha$ in the metric photographs is less than a factor of 3 (Table 1). As a test of internal consistency of our counts, we have compared the average density of panoramic photographs and that of metric photographs for the areas of overlap; both densities match within a statistical error. A variation of a factor of 2 between adjacent photographs in Oceanus Procellarum is also found in the work by Young (1977). Therefore we consider that this regional variation is statistically significant.

\subsection{The crater size-frequency distribution in young craters}

First we test the endogenic crater hypothesis (Kuiper et al., 1966; Chapman et al., 1970; Schultz et al., 1976) on the basis of our crater size-frequency distributions in young craters. In Figs. 3 and 5, the steep slope segments are iden- 
Table 2. Incremental numbers of all crater counting. Boxes indicate bins adopted for $\chi^{2}$ test in Table 1 .

\begin{tabular}{|c|c|c|c|c|c|c|c|c|c|c|c|c|c|c|}
\hline \multicolumn{3}{|c|}{ LO5H127 } & \multicolumn{3}{|c|}{ LO5H153 } & \multicolumn{3}{|c|}{ LO4H121 } & \multicolumn{3}{|c|}{ AS15-2056 } & \multicolumn{3}{|c|}{ AS15-2060 } \\
\hline Bin diameter, $\mathrm{km}$ & $\begin{array}{c}\text { Number of } \\
\text { craters per } \\
\text { bin }\end{array}$ & $\begin{array}{c}\text { Surface } \\
\text { area, } \mathrm{km}^{2}\end{array}$ & Bin diameter, $\mathrm{km}$ & $\begin{array}{c}\text { Number of } \\
\text { craters per } \\
\text { bin }\end{array}$ & $\begin{array}{l}\text { Surface } \\
\text { area, } \mathrm{km}^{2}\end{array}$ & Bin diameter, $\mathrm{km}$ & $\begin{array}{c}\text { Number of } \\
\text { craters per } \\
\text { bin }\end{array}$ & $\begin{array}{c}\text { Surface } \\
\text { area, } \mathrm{km}^{2}\end{array}$ & Bin diameter, $\mathrm{km}$ & $\begin{array}{c}\text { Number of } \\
\text { craters per } \\
\text { bin }\end{array}$ & $\begin{array}{c}\text { Surface } \\
\text { area, } \mathrm{km}^{2}\end{array}$ & Bin diameter, $\mathrm{km}$ & $\begin{array}{c}\begin{array}{c}\text { Number of } \\
\text { craters per } \\
\text { bin }\end{array} \\
\end{array}$ & $\begin{array}{c}\text { Surface } \\
\text { area, }^{2} \mathrm{~km}^{2}\end{array}$ \\
\hline $0.059-0.080$ & 111 & 136 & $0.042-0.052$ & 1602 & 285 & $0.657-0.921$ & 16 & 9420 & $0.76-1.06$ & 317 & 25800 & $0.75-1.05$ & 170 & 25700 \\
\hline $0.080-0.109$ & 42 & 136 & $0.052-0.066$ & 1026 & 285 & $0.921-1.29$ & 9 & 9420 & $1.06-1.48$ & 105 & 25800 & $1.05-1.47$ & 103 & 25700 \\
\hline $0.109-0.150$ & 15 & 136 & $0.066-0.086$ & 670 & 285 & $1.29-1.82$ & 2 & 9420 & $1.48-2.08$ & 41 & 25800 & $1.47-2.06$ & 28 & 25700 \\
\hline $0.150-0.209$ & 2 & 136 & $0.086-0.114$ & 506 & 285 & $1.82-2.57$ & 1 & 9420 & $2.08-2.92$ & 13 & 25800 & $2.06-2.90$ & 2 & 25700 \\
\hline $0.209-0.296$ & 1 & 136 & $0.114-0.153$ & 286 & 285 & & & & $2.92-4.11$ & 3 & 25800 & $2.90-4.09$ & 2 & 25700 \\
\hline & & & $0.153-0.209$ & 126 & 285 & & & & $4.11-5.80$ & 1 & 25800 & $4.09-5.76$ & 1 & 25700 \\
\hline & & & $0.209-0.288$ & 32 & 285 & & & & $5.80-8.19$ & 1 & 25800 & $5.76-8.14$ & 1 & 25700 \\
\hline & & & $0.288-0.400$ & 19 & 285 & & & & $8.19-11.6$ & 2 & 25800 & $8.14-11.5$ & 0 & 25700 \\
\hline & & & $0.400-0.559$ & 2 & 285 & & & & $11.6-16.3$ & 1 & 25800 & $11.5-16.2$ & 0 & 25700 \\
\hline & & & $0.559-0.783$ & 4 & 285 & & & & $16.3-23.1$ & 0 & 25800 & $16.2-23.0$ & 0 & 25700 \\
\hline & & & $0.783-1.11$ & 1 & 285 & & & & $23.1-32.7$ & 1 & 25800 & $23.0-32.4$ & 0 & 25700 \\
\hline & & & & & & & & & & & & $32.4-45.8$ & 1 & 25700 \\
\hline
\end{tabular}

\begin{tabular}{|c|c|c|c|c|c|c|c|c|c|c|c|c|c|c|}
\hline \multicolumn{3}{|c|}{ AS15-2064 } & \multicolumn{3}{|c|}{ AS15-2068 } & \multicolumn{3}{|c|}{ AS15-2072 } & \multicolumn{3}{|c|}{ AS15-2076 } & \multicolumn{3}{|c|}{ AS15-2080 } \\
\hline $0.75-1.05$ & 179 & 25800 & $0.75-1.04$ & 157 & 25800 & $0.74-1.04$ & 202 & 25500 & $0.75-1.05$ & 247 & 26600 & $0.73-1.03$ & 237 & 25700 \\
\hline $1.05-1.47$ & 77 & 25800 & $1.04-1.47$ & 56 & 25800 & $1.04-1.46$ & 56 & 25500 & $1.05-1.48$ & 95 & 26600 & $1.03-1.45$ & 109 & 25700 \\
\hline $1.47-2.07$ & 16 & 25800 & $1.47-2.06$ & 21 & 25800 & $1.46-2.06$ & 6 & 25500 & $1.48-2.09$ & 22 & 26600 & $1.45-2.05$ & 38 & 25700 \\
\hline $2.07-2.91$ & 6 & 25800 & $2.06-2.91$ & 7 & 25800 & $2.06-2.90$ & 8 & 25500 & $2.09-2.95$ & 4 & 26600 & $2.05-2.89$ & 9 & 25700 \\
\hline $2.91-4.10$ & 2 & 25800 & $2.91-4.10$ & 2 & 25800 & $2.90-4.09$ & 1 & 25500 & $2.95-4.17$ & 1 & 26600 & $2.89-4.08$ & 3 & 25700 \\
\hline $4.10-5.79$ & 1 & 25800 & $4.10-5.80$ & 1 & 25800 & $4.09-5.78$ & 0 & 25500 & $4.17-5.89$ & 3 & 26600 & $4.08-5.77$ & 4 & 25700 \\
\hline $5.79-8.18$ & 1 & 25800 & & & & $5.78-8.17$ & 1 & 25500 & $5.89-8.33$ & 0 & 26600 & $5.77-8.15$ & 0 & 25700 \\
\hline $8.18-11.6$ & 0 & 25800 & & & & $8.17-11.5$ & 0 & 25500 & $8.33-11.8$ & 1 & 26600 & $8.15-11.5$ & 1 & 25700 \\
\hline $11.6-16.3$ & 0 & 25800 & & & & $11.5-16.3$ & 0 & 25500 & $11.8-16.7$ & 0 & 26600 & & & \\
\hline $16.3-23.1$ & 0 & 25800 & & & & $16.3-23.1$ & 1 & 25500 & $16.7-23.5$ & 1 & 26600 & & & \\
\hline $23.1-32.7$ & 1 & 25800 & & & & & & & $23.5-33.2$ & 1 & 26600 & & & \\
\hline
\end{tabular}

\begin{tabular}{|c|c|c|c|c|c|c|c|c|c|c|c|c|c|c|c|}
\hline \multicolumn{3}{|c|}{ AS15-2480 } & \multicolumn{3}{|c|}{ AS15-2484 } & \multicolumn{3}{|c|}{ AS15-2746 } & \multicolumn{3}{|c|}{ AS15-2748 } & \multicolumn{4}{|c|}{ AS15-2490 } \\
\hline $0.72-1.01$ & 171 & 18600 & $0.71-1.00$ & 97 & 14600 & $0.71-1.00$ & 155 & 18300 & $0.72-1.01$ & 122 & 18600 & 0.7 & -1.00 & 146 & 24600 \\
\hline $1.01-1.42$ & 41 & 18600 & $1.00-1.41$ & 25 & 14600 & $1.00-1.42$ & 24 & 18300 & $1.01-1.43$ & 41 & 18600 & 1.0 & -1.41 & 53 & 24600 \\
\hline $1.42-2.00$ & 37 & 18600 & $1.41-1.99$ & 9 & 14600 & $1.42-2.00$ & 12 & 18300 & $1.43-2.02$ & 6 & 18600 & 1.4 & -1.99 & 15 & 24600 \\
\hline $2.00-2.82$ & 11 & 18600 & $1.99-2.82$ & 3 & 14600 & $2.00-2.83$ & 5 & 18300 & $2.02-2.86$ & 6 & 18600 & 1.9 & -2.82 & 7 & 24600 \\
\hline $2.82-3.98$ & 2 & 18600 & $2.82-3.98$ & 2 & 14600 & $2.83-4.00$ & 2 & 18300 & $2.86-4.04$ & 2 & 18600 & 2.8 & -3.99 & 2 & 24600 \\
\hline $3.98-5.63$ & 1 & 18600 & $3.98-5.63$ & 1 & 14600 & $4.00-5.65$ & 3 & 18300 & $4.04-5.71$ & 3 & 18600 & 3.9 & -5.65 & 4 & 24600 \\
\hline $5.63-$ & 6 & 18600 & & & & $5.65-7.99$ & 2 & 18300 & $5.71-8.08$ & 1 & 18600 & 5.6 & 7.99 & 2 & 24600 \\
\hline
\end{tabular}

\begin{tabular}{|c|c|c|c|c|c|c|c|c|c|c|c|c|c|c|}
\hline \multicolumn{3}{|c|}{ AS15-1838 } & \multicolumn{3}{|c|}{ AS15-1842 } & \multicolumn{3}{|c|}{ AS15-1846 } & \multicolumn{3}{|c|}{ AS15-1850 } & \multicolumn{3}{|c|}{ AS $15-0260$} \\
\hline Bin diameter, $\mathrm{km}$ & $\begin{array}{c}\text { Number of } \\
\text { craters per } \\
\text { bin }\end{array}$ & $\begin{array}{c}\text { Surface } \\
\text { area, } \mathrm{km}^{2}\end{array}$ & Bin diameter, km & $\begin{array}{c}\text { Number of } \\
\text { craters per } \\
\text { bin }\end{array}$ & $\begin{array}{c}\text { Surface } \\
\text { area, } \mathrm{km}^{2}\end{array}$ & Bin diameter, $\mathrm{km}$ & $\begin{array}{c}\text { Number of } \\
\text { craters per } \\
\text { bin }\end{array}$ & $\begin{array}{c}\text { Surface } \\
\text { area, } \mathrm{km}^{2}\end{array}$ & Bin diameter, $\mathrm{km}$ & $\begin{array}{c}\text { Number of } \\
\text { craters per } \\
\text { bin }\end{array}$ & $\begin{array}{c}\text { Surface } \\
\text { area, } \mathrm{km}^{2}\end{array}$ & Bin diameter, km & $\begin{array}{c}\text { Number of } \\
\text { craters per } \\
\text { bin }\end{array}$ & $\begin{array}{c}\text { Surface } \\
\text { area, } \mathrm{km}^{2}\end{array}$ \\
\hline $0.72-1.01$ & 203 & 25200 & $0.73-1.03$ & 139 & 26100 & $0.72-1.02$ & 232 & 26000 & $0.72-1.02$ & 196 & 16800 & $0.213-0.284$ & 281 & 640 \\
\hline $1.01-1.42$ & 82 & 25200 & $1.03-1.45$ & 53 & 26100 & $1.02-1.45$ & 104 & 26000 & $1.02-1.44$ & 81 & 16800 & $0.284-0.383$ & 227 & 640 \\
\hline $1.42-2.01$ & 29 & 25200 & $1.45-2.05$ & 23 & 26100 & $1.45-2.05$ & 20 & 26000 & $1.44-2.04$ & 14 & 16800 & $0.383-0.523$ & 43 & 640 \\
\hline $2.01-2.83$ & 10 & 25200 & $2.05-2.90$ & 12 & 26100 & $2.05-2.89$ & 6 & 26000 & $2.04-2.89$ & 3 & 16800 & $0.523-0.721$ & 12 & 640 \\
\hline $2.83-4.00$ & 4 & 25200 & $2.90-4.10$ & 2 & 26100 & $2.89-4.09$ & 0 & 26000 & $2.89-4.09$ & 1 & 16800 & $0.721-1.00$ & 3 & 640 \\
\hline $4.00-5.65$ & 2 & 25200 & $4.10-5.79$ & 0 & 26100 & $4.09-5.79$ & 2 & 26000 & $4.09-5.78$ & 3 & 16800 & $1.00-1.41$ & 1 & 640 \\
\hline $5.65-7.99$ & 0 & 25200 & $5.79-8.19$ & 0 & 26100 & $5.79-8.18$ & 1 & 26000 & & & & & & \\
\hline $7.99-11.3$ & 0 & 25200 & $8.19-11.6$ & 0 & 26100 & $8.18-11.6$ & 0 & 26000 & & & & & & \\
\hline $11.3-16.0$ & 0 & 25200 & $11.6-16.4$ & 0 & 26100 & $11.6-16.4$ & 0 & 26000 & & & & & & \\
\hline $16.0-22.6$ & 0 & 25200 & $16.4-23.1$ & 0 & 26100 & $16.4-23.2$ & 1 & 26000 & & & & & & \\
\hline $22.6-32.0$ & & 25200 & $23.1-32.7$ & & 26100 & & & & & & & & & \\
\hline
\end{tabular}

\begin{tabular}{|c|c|c|c|c|c|c|c|c|c|c|c|c|c|c|c|c|c|c|}
\hline \multicolumn{4}{|c|}{ AS15-0264 } & \multicolumn{4}{|c|}{ AS15-0268 } & \multicolumn{3}{|c|}{ AS15-0272 } & \multicolumn{4}{|c|}{ AS15-0276 } & \multicolumn{4}{|c|}{ AS15-0280 } \\
\hline 0.205 & -0.272 & 259 & 586 & 0.209 & -0.278 & 274 & 629 & $0.207-0.276$ & 281 & 595 & 0.212 & -0.284 & 403 & 671 & 0.217 & -0.292 & 416 & 707 \\
\hline 0.272 & -0.367 & 106 & 586 & 0.278 & -0.377 & 130 & 629 & $0.276-0.374$ & 95 & 595 & 0.284 & -0.386 & 112 & 671 & 0.292 & -0.398 & 124 & 707 \\
\hline 0.367 & -0.501 & 32 & 586 & 0.377 & -0.515 & 46 & 629 & $0.374-0.513$ & 34 & 595 & 0.386 & -0.529 & 35 & 671 & 0.398 & -0.547 & 58 & 707 \\
\hline 0.501 & -0.690 & 3 & 586 & 0.515 & -0.711 & 8 & 629 & $0.513-0.708$ & 7 & 595 & 0.529 & -0.732 & 9 & 671 & 0.547 & -0.758 & 18 & 707 \\
\hline 0.690 & -0.959 & 2 & 586 & 0.711 & -0.99 & 5 & 629 & $0.708-0.985$ & 4 & 595 & 0.732 & -1.02 & 4 & 671 & 0.758 & -1.058 & 1 & 707 \\
\hline 0.959 & -1.33 & 2 & 586 & 0.99 & -1.40 & 3 & 629 & $0.985-1.37$ & 3 & 595 & 1.02 & -1.44 & 1 & 671 & 1.058 & -1.47 & 2 & 707 \\
\hline 1.33 & -1.88 & 1 & 586 & & & & & $1.37-1.93$ & 0 & 595 & & & & & 1.47 & -2.08 & 1 & 707 \\
\hline & & & & & & & & $1.93-2.71$ & 1 & 595 & & & & & & & & \\
\hline & & & & & & & & $2.71-3.83$ & 1 & 595 & & & & & & & & \\
\hline
\end{tabular}

tified in the crater size-frequency distributions on the ejecta blankets of Tycho and Copernicus craters. While the steep slope on Tycho ejecta blanket is not perceived by some previous work (Basaltic Volcanism Study Project, 1981), the steep slope segment can be recognized in not only our results but also others (Young, 1977) (Figs. 3(a) and (b)). These results indicate that the endogenic crater hypothesis is implausible, because no volcanic activity is reported on the ejecta blankets of young Tycho and Copernicus craters. Even though post-impact volcanism is suggested for the floors of these two craters (Basaltic Volcanism Study Project, 1981), the observed size-frequency distribution on the floor of the Copernicus crater (Table 2 and Fig. 4) is nearly identical with that on the ejecta blanket (Table 2 and Fig. 5).

\subsection{A comparison with geophysical data sets}

We consider the second hypothesis that attributes the steep segment of the crater size-frequency distributions to variable strength of target (Gault, 1970; Schultz et al., 1977; Chapman et al., 1979). Unfortunately, our knowledge on the subsurface structure under the lunar maria is limited. Instead 
Table 2. (continued).

\begin{tabular}{|c|c|c|c|c|c|c|c|c|c|c|c|c|c|c|c|c|c|c|}
\hline \multicolumn{3}{|c|}{ AS15-0284 } & \multicolumn{4}{|c|}{ AS15-0288 } & \multicolumn{4}{|c|}{ AS15-0292 } & \multicolumn{4}{|c|}{ AS15-0296 } & \multicolumn{4}{|c|}{ AS15-0300 } \\
\hline $0.211-0.284$ & 426 & 670 & 0.210 & -0.282 & 111 & 669 & 0.210 & -0.283 & 129 & 677 & 0.206 & -0.279 & 289 & 665 & 0.210 & -0.284 & 463 & 703 \\
\hline $0.284-0.387$ & 245 & 670 & 0.282 & -0.385 & 72 & 669 & 0.283 & -0.386 & 89 & 677 & 0.279 & -0.381 & 156 & 665 & 0.284 & -0.390 & 252 & 703 \\
\hline $0.387-0.532$ & 98 & 670 & 0.385 & -0.531 & 41 & 669 & 0.386 & -0.533 & 31 & 677 & 0.381 & -0.526 & 82 & 665 & 0.390 & -0.539 & 109 & 703 \\
\hline $0.532-0.737$ & 34 & 670 & 0.531 & -0.736 & 8 & 669 & 0.533 & -0.739 & 18 & 677 & 0.526 & -0.730 & 27 & 665 & 0.539 & -0.749 & 39 & 703 \\
\hline $0.737-1.03$ & 14 & 670 & 0.736 & -1.03 & 4 & 669 & 0.739 & -1.03 & 9 & 677 & 0.730 & -1.02 & 10 & 665 & 0.749 & -1.05 & 6 & 703 \\
\hline $1.03-1.46$ & 4 & 670 & 1.03 & -1.43 & 0 & 669 & 1.03 & -1.46 & 1 & 677 & 1.02 & -1.43 & 4 & 665 & 1.05 & -1.48 & 3 & 703 \\
\hline & & & 1.43 & -2.02 & 1 & 669 & & & & & 1.43 & -2.02 & 2 & 665 & & & & \\
\hline
\end{tabular}

\begin{tabular}{|c|c|c|c|c|c|c|c|c|c|c|c|c|c|c|}
\hline \multicolumn{3}{|c|}{ AS15-0304 } & \multicolumn{3}{|c|}{ AS15-0308 } & \multicolumn{3}{|c|}{ AS15-0312 } & \multicolumn{3}{|c|}{ AS15-0316 } & \multicolumn{3}{|c|}{ AS15-0320 } \\
\hline Bin diameter, $\mathrm{km}$ & $\begin{array}{c}\text { Number of } \\
\text { craters per } \\
\text { bin }\end{array}$ & $\begin{array}{c}\text { Surface } \\
\text { area, } \mathrm{km}^{2}\end{array}$ & Bin diameter, $\mathrm{km}$ & $\begin{array}{c}\text { Number of } \\
\text { craters per } \\
\text { bin }\end{array}$ & $\begin{array}{c}\text { Surface } \\
\text { area, } \mathrm{km}^{2}\end{array}$ & Bin diameter, $\mathrm{km}$ & $\begin{array}{c}\text { Number of } \\
\text { craters per } \\
\text { bin }\end{array}$ & $\begin{array}{c}\text { Surface } \\
\text { area, } \mathrm{km}^{2}\end{array}$ & Bin diameter, $\mathrm{km}$ & $\begin{array}{c}\text { Number of } \\
\text { craters per } \\
\text { bin }\end{array}$ & $\begin{array}{c}\text { Surface } \\
\text { area, } \mathrm{km}^{2}\end{array}$ & Bin diameter, $\mathrm{km}$ & $\begin{array}{c}\text { Number of } \\
\text { craters per } \\
\text { bin }\end{array}$ & $\begin{array}{c}\text { Surface } \\
\text { area, } \mathrm{km}^{2}\end{array}$ \\
\hline $0.200-0.272$ & 442 & 644 & $0.197-0.267$ & 356 & 622 & $0.193-0.263$ & 452 & 613 & $0.194-0.264$ & 521 & 624 & $0.185-0.252$ & 200 & 568 \\
\hline $0.272-0.373$ & 222 & 644 & $0.267-0.367$ & 178 & 622 & $0.263-0.362$ & 291 & 613 & $0.264-0.363$ & 286 & 624 & $0.252-0.347$ & 125 & 568 \\
\hline $0.373-0.515$ & 114 & 644 & $0.367-0.507$ & 70 & 622 & $0.362-0.501$ & 157 & 613 & $0.363-0.504$ & 108 & 624 & $0.347-0.481$ & 59 & 568 \\
\hline $0.515-0.716$ & 33 & 644 & $0.507-0.706$ & 17 & 622 & $0.501-0.697$ & 38 & 613 & $0.504-0.702$ & 21 & 624 & $0.481-0.671$ & 23 & 568 \\
\hline $0.716-1.00$ & 5 & 644 & $0.706-0.988$ & 2 & 622 & $0.697-0.977$ & 13 & 613 & $0.702-0.984$ & 10 & 624 & $0.671-0.941$ & 7 & 568 \\
\hline $1.00-1.40$ & 4 & 644 & $0.988-1.38$ & 1 & 622 & $0.977-1.37$ & 2 & 613 & $0.984-1.38$ & 3 & 624 & $0.941-1.32$ & 1 & 568 \\
\hline $1.40-1.98$ & 1 & 644 & $1.38-1.95$ & 1 & 622 & $1.37-1.94$ & 1 & 613 & $1.38-1.95$ & 1 & 624 & $1.32-1.85$ & 0 & 568 \\
\hline & & & & & & & & & & & & $\begin{array}{l}1.85-2.61 \\
2.61-3.69 \\
3.69-5.22\end{array}$ & $\begin{array}{l}1 \\
1 \\
1\end{array}$ & $\begin{array}{l}568 \\
568 \\
568\end{array}$ \\
\hline
\end{tabular}

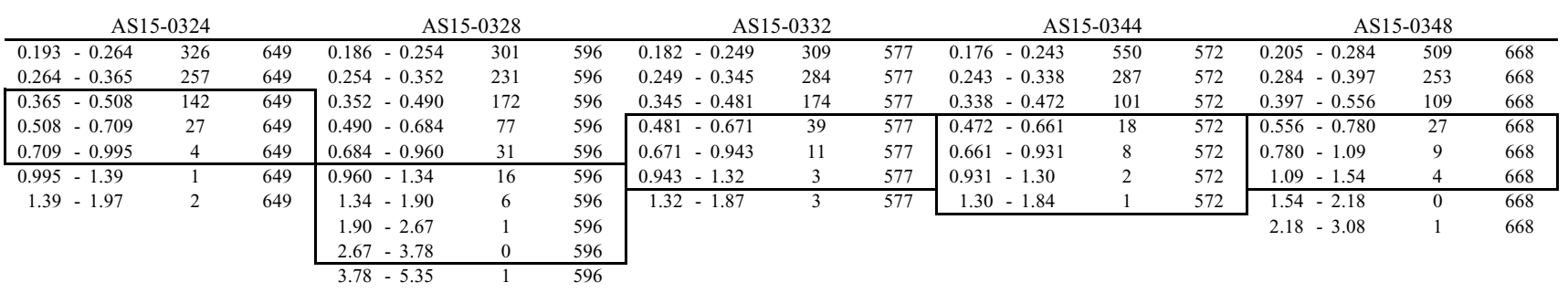

\begin{tabular}{|c|c|c|c|c|c|c|c|c|c|c|c|c|c|c|c|c|c|}
\hline \multicolumn{4}{|c|}{ AS15-0352 } & \multicolumn{3}{|c|}{ AS15-0356 } & \multicolumn{3}{|c|}{ AS15-0358 } & \multicolumn{4}{|c|}{ AS15-0360 } & \multicolumn{4}{|c|}{ AS15-0362 } \\
\hline 0.185 & -0.257 & 413 & 600 & $0.181-0.251$ & 502 & 587 & $0.181-0.253$ & 490 & 613 & 0.159 & -0.222 & 517 & 495 & 0.158 & -0.221 & 711 & 505 \\
\hline 0.257 & -0.359 & 140 & 600 & $0.251-0.352$ & 169 & 587 & $0.253-0.354$ & 204 & 613 & 0.222 & -0.310 & 231 & 495 & 0.221 & -0.309 & 283 & 505 \\
\hline 0.359 & -0.502 & 34 & 600 & $0.352-0.493$ & 59 & 587 & $0.354-0.496$ & 68 & 613 & 0.310 & -0.435 & 90 & 495 & 0.309 & -0.434 & 104 & 505 \\
\hline 0.502 & -0.705 & 7 & 600 & $0.493-0.697$ & 8 & 587 & $0.496-0.697$ & 14 & 613 & 0.435 & -0.611 & 17 & 495 & 0.434 & -0.611 & 25 & 505 \\
\hline 0.705 & -0.994 & 3 & 600 & & & & $0.697-0.983$ & 4 & 613 & 0.611 & -0.861 & 8 & 495 & 0.611 & -0.862 & 7 & 505 \\
\hline 0.994 & -1.41 & 1 & 600 & & & & $0.983-1.38$ & 2 & 613 & 0.861 & -1.21 & 1 & 495 & 0.862 & -1.21 & 1 & 505 \\
\hline & & & & & & & $1.38-1.95$ & 1 & 613 & 1.21 & -1.71 & 1 & 495 & 1.21 & -1.71 & 1 & 505 \\
\hline & & & & & & & & & & 1.71 & -2.41 & 1 & 495 & 1.71 & -2.42 & 0 & 505 \\
\hline & & & & & & & & & & 2.41 & -3.41 & 1 & 495 & 2.42 & -3.42 & 0 & 505 \\
\hline & & & & & & & & & & & & & & 3.42 & -4.84 & 0 & 505 \\
\hline & & & & & & & & & & & & & & 4.84 & -6.84 & 1 & 505 \\
\hline
\end{tabular}

\begin{tabular}{|c|c|c|c|c|c|c|c|c|}
\hline \multicolumn{3}{|c|}{ AS15-0364 } & \multicolumn{3}{|c|}{ AS15-0366 } & \multicolumn{3}{|c|}{ AS15-0370 } \\
\hline Bin diameter, $\mathrm{km}$ & $\begin{array}{c}\begin{array}{c}\text { Number of } \\
\text { craters per } \\
\text { bin }\end{array} \\
\end{array}$ & $\begin{array}{c}\text { Surface } \\
\text { area, } \mathrm{km}^{2}\end{array}$ & Bin diameter, $\mathrm{km}$ & $\begin{array}{c}\text { Number of } \\
\text { craters per } \\
\text { bin }\end{array}$ & $\begin{array}{c}\text { Surface } \\
\text { area, } \mathrm{km}^{2}\end{array}$ & Bin diameter, $\mathrm{km}$ & $\begin{array}{c}\text { Number of } \\
\text { craters per } \\
\text { bin }\end{array}$ & $\begin{array}{c}\text { Surface } \\
\text { area, } \mathrm{km}^{2}\end{array}$ \\
\hline $0.154-0.215$ & 775 & 474 & $0.157-0.221$ & 839 & 506 & $0.152-0.214$ & 933 & 457 \\
\hline $0.215-0.302$ & 307 & 474 & $0.221-0.311$ & 429 & 506 & $0.214-0.303$ & 555 & 457 \\
\hline $0.302-0.425$ & 106 & 474 & $0.311-0.438$ & 149 & 506 & $0.303-0.428$ & 128 & 457 \\
\hline $0.425-0.598$ & 29 & 474 & $0.438-0.616$ & 56 & 506 & $0.428-0.603$ & 41 & 457 \\
\hline $0.598-0.844$ & 6 & 474 & $0.616-0.871$ & 16 & 506 & $0.603-0.854$ & 7 & 457 \\
\hline $0.844-1.19$ & 2 & 474 & $0.871-1.22$ & 4 & 506 & $0.854-1.20$ & 1 & 457 \\
\hline & & & $1.22-1.73$ & 0 & 506 & $1.20-1.70$ & 1 & 457 \\
\hline
\end{tabular}

we examine the correlation of the crater size-frequency distribution with thickness of mare basalt (DeHon, 1979), topography (Smith et al., 1997), and Bouguer gravity anomaly (Konopliv et al., 1998; Wieczorek and Phillips, 1998; Konopliv and Yuan, 1999) assuming that these geophysical data sets are influenced by crustal structure.

The results are shown in Figs. 7, 8, and 9. In Fig. 7, we adopt 13 craters that lie in an area between $10^{\circ} \mathrm{W}$ and $70^{\circ} \mathrm{W}$, and between $26^{\circ} \mathrm{N}$ and $32^{\circ} \mathrm{N}$ from the list by DeHon (1979). The mare thickness estimated from those 13 craters is shown as open squares in Fig. 7 by the longitude regardless of the latitude. In this figure, the mare thickness appears to have no correlation with crater size-frequency distributions of either metric or panoramic photographs. The topography and
Bouguer gravity anomaly at the center of each photograph are calculated by using sets of spherical harmonic coefficients, GLTM-2 (Smith et al., 1997) and JGL100J1 (Konopliv et al., 1998; Wieczorek and Phillips, 1998; Konopliv and Yuan, 1999), respectively. It is evident in Figs. 8 and 9 that no significant correlation is found between the crater sizefrequency distributions and the topography or Bouguer gravity anomaly. Consequently correlations calculated for these data sets are low (Table 3). Thus, the variable target hypothesis is not supported from the present data sets.

\subsection{A comparison with geologic units}

If the crater size-frequency distribution corresponds to that of projectiles, the distribution is necessarily a function of surface age until the density reaches in equilibrium. Therefore a 
(a)

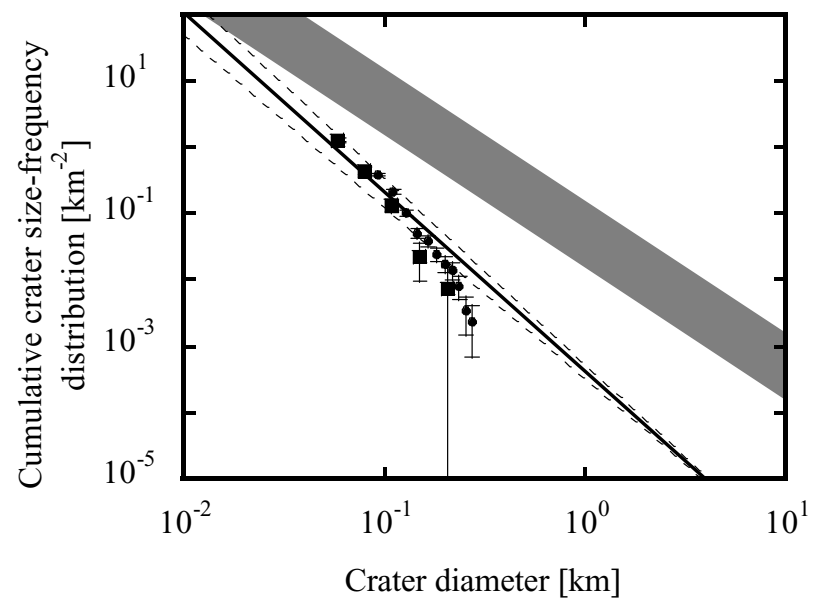

(b)

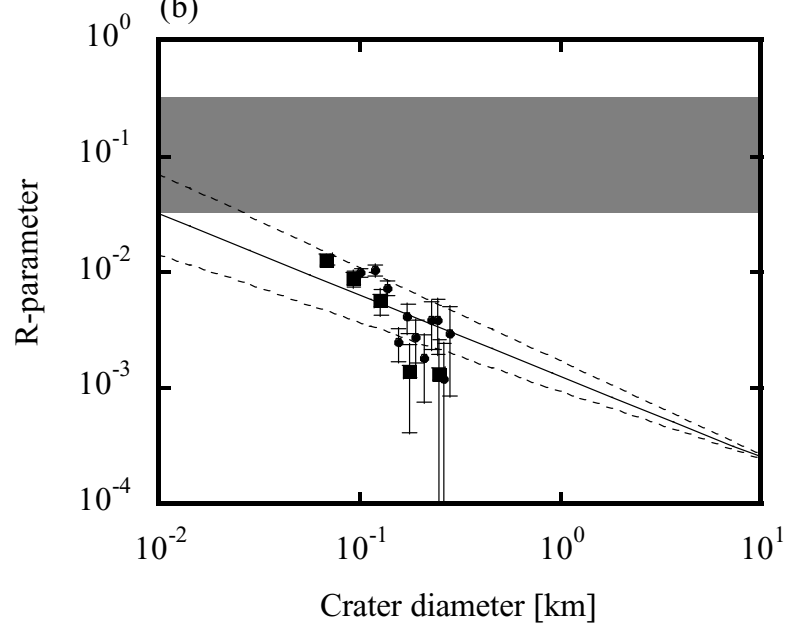

Fig. 3. A crater size-frequency distribution on the ejecta blanket surrounding Tycho crater (LO5H127). Solid circles and squares are the crater size-frequency distributions from Young (1977) and this work, respectively. Solid and dotted lines are an average and errors determined by Guiness and Arvidson (1977). The shaded band indicates crater equilibrium for which the value of $\alpha$ is between 0.15 and 0.015 (Melosh, 1989). (a) Cumulative, and (b) R plots (Crater Analysis Techniques Working Group, 1979; Strom et al., 1992).

test of this hypothesis is to compare the crater size-frequency distribution of the photographs in Table 1 with radiometric age at each location. For example, Young (1977) argues that a ratio of crater number density for Copernicus to that for Tycho at a-100-m diameter is consistent with approximate ages of these craters. While our counts reveal a similar ratio at this diameter (Figs. 3 and 5), it is obvious from the low negative $\beta$ values in Table 1 that the ratio strongly depends on diameter.

For Oceanus Procellarum and Mare Imbrium, a direct comparison between the size-frequency distribution and the radiometric age is difficult because of a lack of samples to be measured. Instead we compare the $\alpha$ value of each photograph with classification in geologic maps (Pieters et al., 1975; Head et al., 1978; Pieters, 1978; Whitford-Stark and Head, 1980; Wilhelms et al., 1987) assuming that each geologic unit represents the same surface age (Figs. 10(a), (b),

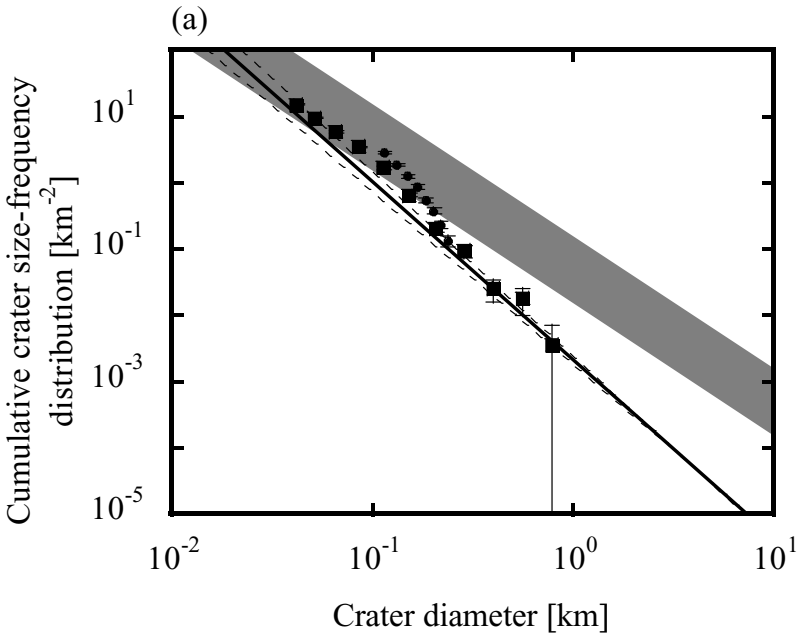

(b)

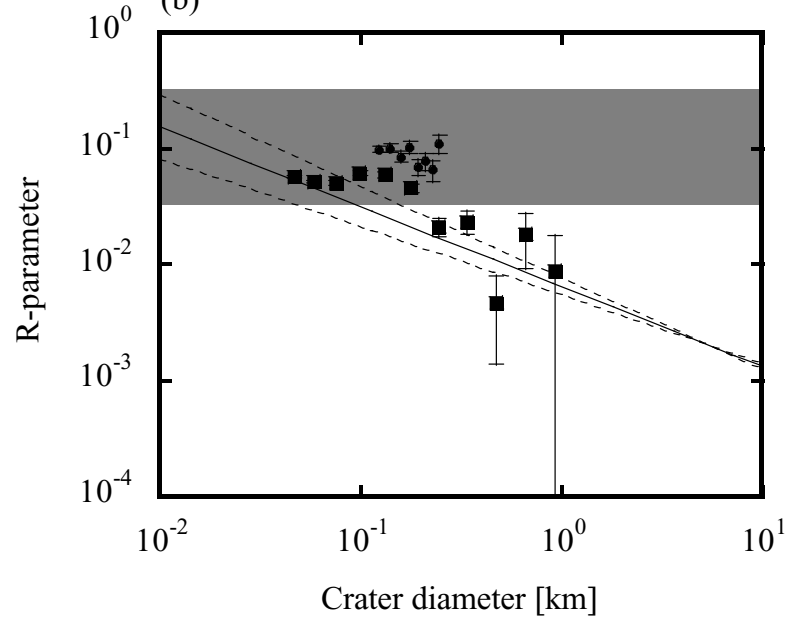

Fig. 4. A crater size-frequency distribution on the floor within Copernicus crater (LO5H153). Lines and symbols are the same as in Fig. 3. (a) Cumulative, and (b) R plots (Crater Analysis Techniques Working Group, 1979; Strom et al., 1992).

and (c)). In Figs. 10(a), (b), and (c), we classify the $\alpha$ values by geologic and spectral units. And also we show an average and a standard deviation of $\alpha$ in the same geologic unit by open squares. Because the standard deviation is much greater than errors of each photograph, no relation is found between the $\alpha$ values and geologic classification. Therefore we conclude that the primary production hypothesis is unlikely.

\subsection{A comparison among panoramic photographs}

The crater size-frequency distributions of the panoramic photographs in Oceanus Procellarum and Mare Imbrium (Fig. 7) can serve as a test of the secondary crater hypothesis. At the first glance, clusters of secondary craters are recognized on the photographs AS15-0280, 0284, 0296, 0300, 0304, 0316, 0328, 0332, 0356, 0358, 0360, 0362, and 0366 (Table 1). While their contribution to the $\alpha$ values is apparently minor except for the photographs AS15-0328 and 0362, it is necessary to take into consideration the possible presence of many isolated secondary craters. Therefore we examine the $\alpha$ value and distance from a local large crater, because the density of small craters is expected to decrease 
(a)

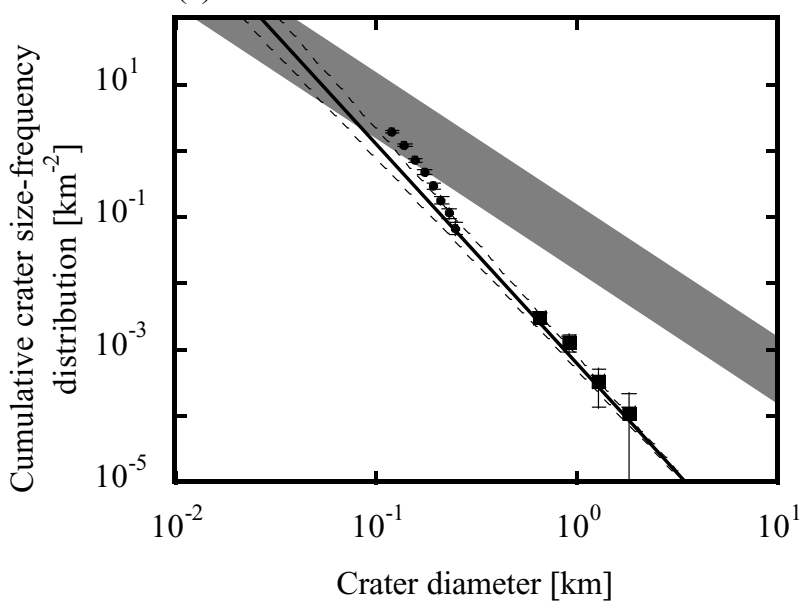

(b)

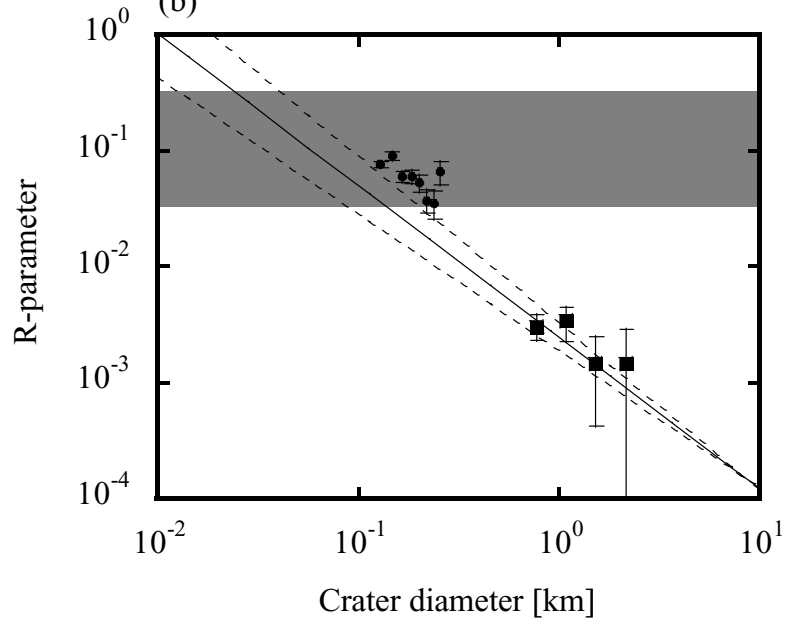

Fig. 5. A crater size-frequency distribution on the ejecta blanket of Copernicus crater (LO4H121). Lines and symbols are the same as in Fig. 3. (a) Cumulative, and (b) R plots (Crater Analysis Techniques Working Group, 1979; Strom et al., 1992).

as the distance increases.

We select 12 large craters with diameter sufficiently large to form secondary craters (Shoemaker, 1965) and examine the crater density with increasing distance from the large crater. They are Archimedes, Aristarchus, DeLisle, Diophantus, Euler, Herodotus, Lambert, Timocharis, Krieger, Lichtenberg, Pytheas (Fig. 2), and Copernicus craters. Then it is found that Aristarchus crater is a possible source of the secondary craters not only because the correlation is the highest (Table 3), but also because the $\alpha$ value decreases with the inverse of distance (Fig. 11). Figure 11 indicates that the secondary craters hypothesis is the most likely to explain the steep slope segment of the crater size-frequency distribution, and that isolated secondary craters play an important role in the crater size-frequency distribution.

\section{Discussion}

\subsection{Elimination of the primary crater hypothesis}

Before the primary production hypothesis is rejected, we should allow for the possibility that the classification in the geologic maps is incorrect. As evident in Table 1, there is

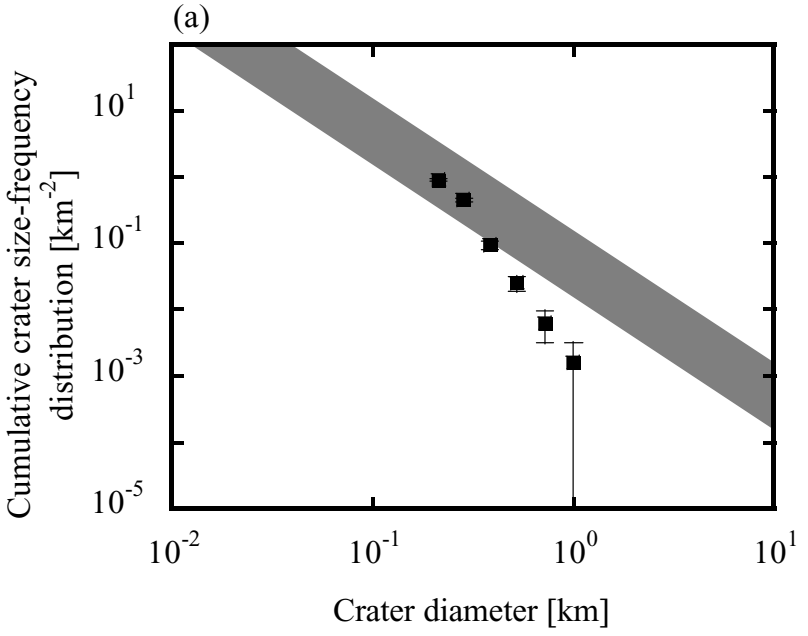

(b)

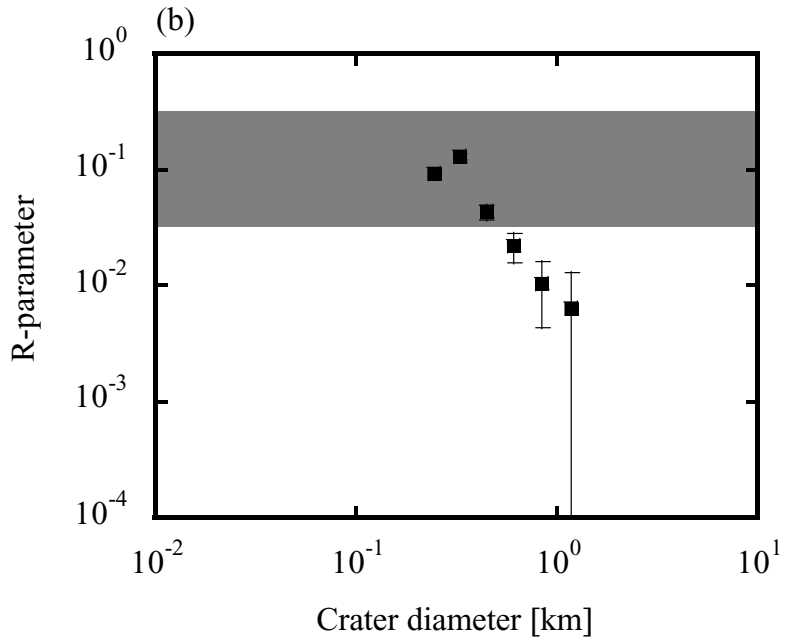

Fig. 6. A crater size-frequency distribution of AS15-0260. Lines and symbols are the same as in Fig. 3. (a) Cumulative, and (b) R plots (Crater Analysis Techniques Working Group, 1979; Strom et al., 1992).

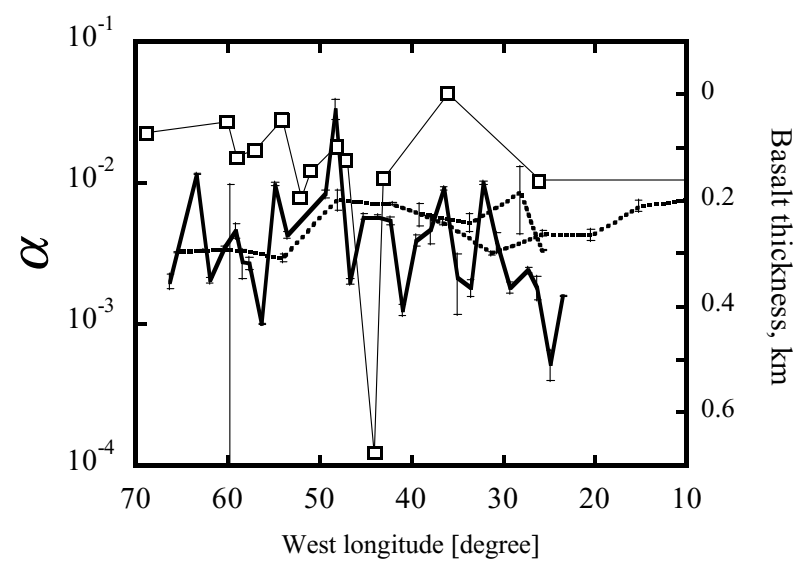

Fig. 7. Regional variation of cumulative crater size-frequency distribution. The thick dotted line is the size-frequency distribution of the panoramic photographs. The thick dotted line is the distribution of the metric 1 photographs, and the second branch is that of metric 2 photographs (Table 1). Thickness of mare basalt estimated by DeHon (1979) is also shown by the thin solid line with open squares. 


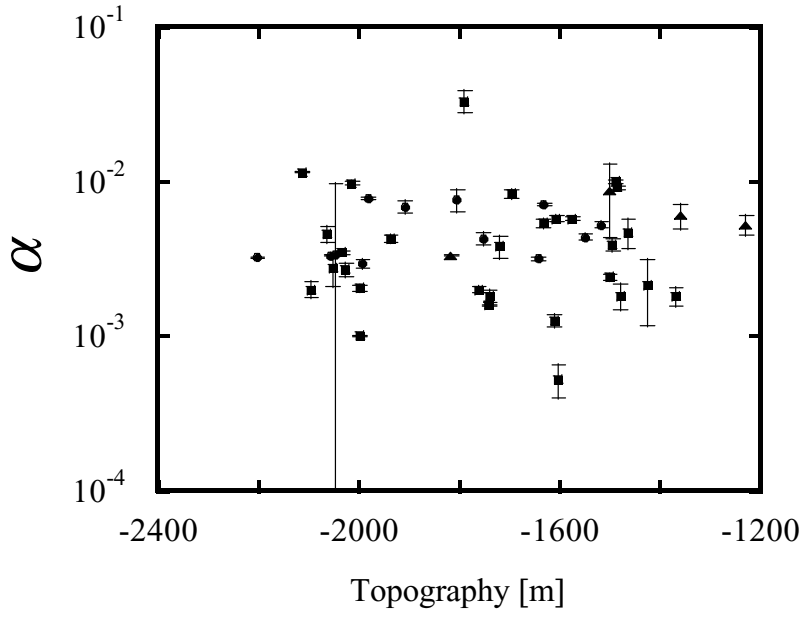

Fig. 8. Cumulative crater size-frequency distributions and topography. Solid circles, triangles, and squares indicate metric 1 and 2 , and panoramic photographs, respectively (Table 1).

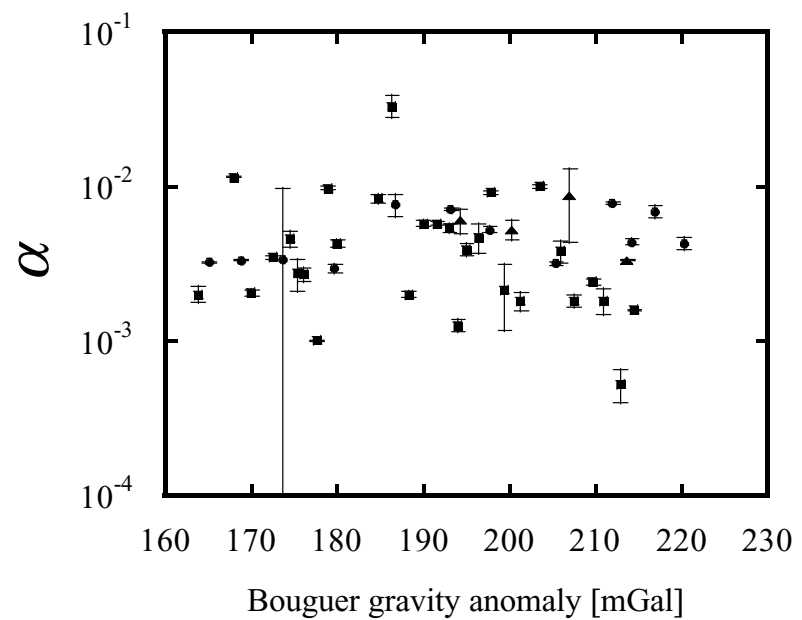

Fig. 9. Cumulative crater size-frequency distributions and Bouguer gravity anomaly. Solid circles, triangles, and squares indicate metric 1 , metric 2 , and panoramic photographs, respectively (Table 1).

Table 3. Correlation of crater size-frequency distribution with other data sets (Smith et al., 1997; Konopliv et al., 1998; Wieczorek and Phillips, 1998)

\begin{tabular}{lcc}
\hline Data set & Correlation & Figure \\
\hline Topography & 0.005 & 8 \\
Bouguer gravity anomaly & 0.051 & 9 \\
Distance from Aristarchus crater & 0.474 & 11 \\
\hline
\end{tabular}

a notable discrepancy among the geologic maps by different workers (Pieters et al., 1975; Head et al., 1978; Pieters, 1978; Whitford-Stark and Head, 1980; Wilhelms et al., 1987). If the steep slope segment of the lunar crater sizefrequency distribution is indeed indicating the surface age as proposed by Neukum and Ivanov (1994), the large variation of $\alpha$ (Fig. 7) suggests that the current geologic maps need to be fully revised, and that the scale of geologic units may be significantly smaller than currently accepted (Hiesinger et al., 2000a, b; Rajmon and Spudis, 2001). Thus, a volcanic history more complicated than our present knowledge (a)

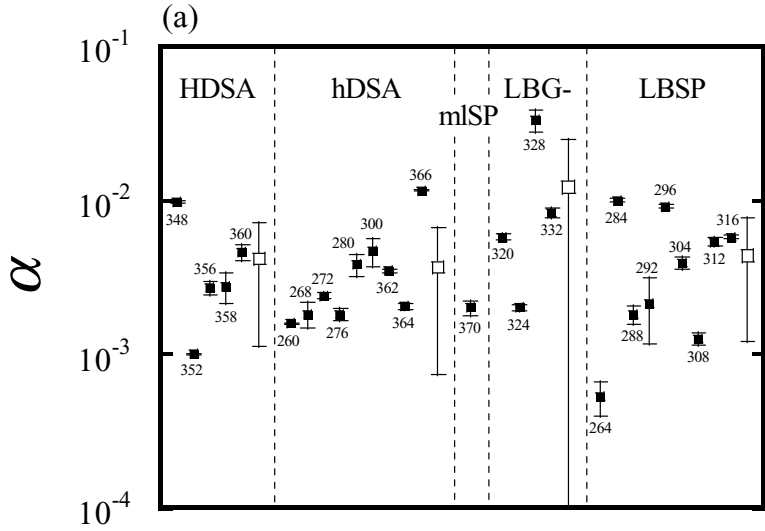

(b)

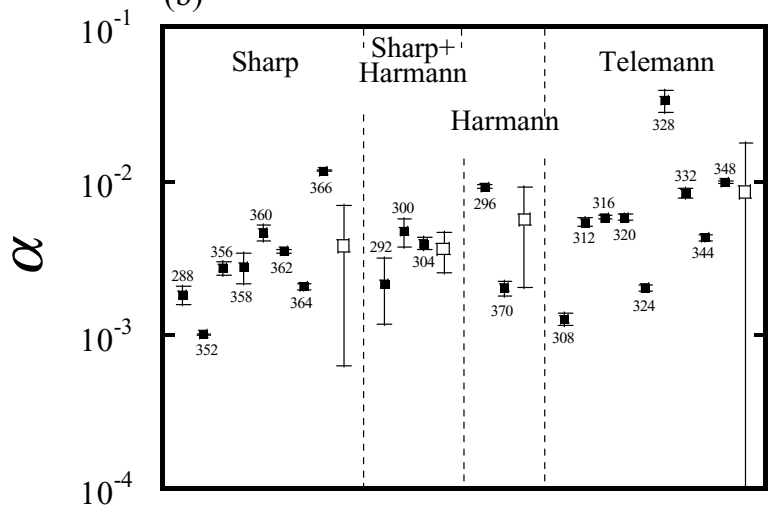

(c)

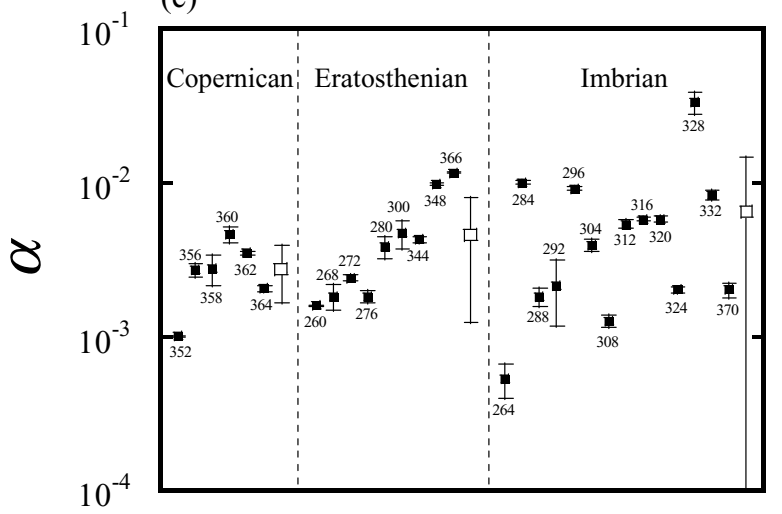

Fig. 10. A comparison of the $\alpha$ values of panoramic photographs (Table 1) with geologic or taxologic units. Numbers next to symbols indicate photograph numbers in Tables 1 and 2. For each unit the average of $\alpha$ values and the standard deviation are shown by open squares. Classifications are based on (a) a spectral map compiled by Wilhelms et al. (1987, pl 4) from Pieters et al., (1975), Head et al. (1978), and Pieters (1978), (b) a geologic map by Whitford-Stark and Head (1980), and (c) a geologic map by Wilhelms et al. (1987, pl. 12).

(Basaltic Volcanism Study Project, 1981) is implied. For example, values of $\alpha$ as low as $1.0 \times 10^{-3}$ (Fig. 7) indicate a surface age as young as that of the Copernicus impact (Table 1). On the other hand, radiometric ages of Apollo 12 samples are concentrated within a narrow range from 3.05 to 3.35 b.y. (Fig. 12) (Basaltic Volcanism Study Project, 1981). Therefore the primary production hypothesis is not supported by 


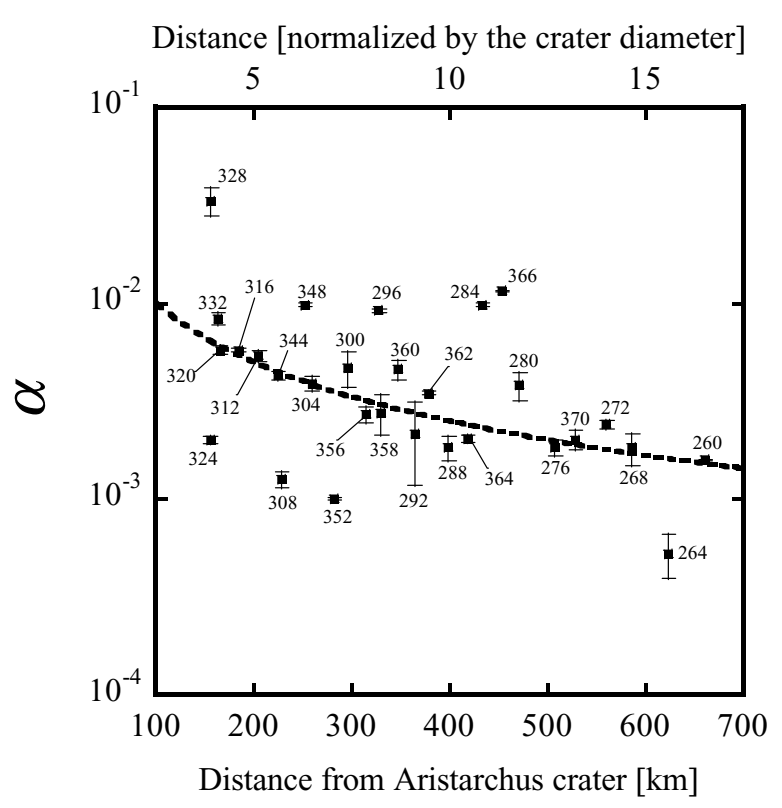

Fig. 11. A variation of $\alpha$ with distance from Aristarchus crater. Dashed line is 25 (normalized distance) $^{-1}$, and numbers next to symbol indicate photograph numbers in Tables 1 and 2. Upper horizontal axis is the distance normalized by the crater diameter $(40 \mathrm{~km})$.

geochemical studies of lunar samples, even though the classification in geologic maps may include significant uncertainty.

So far we have presented evidence that the primary production hypothesis is unlikely. The most important implication of this interpretation is that small craters should not be taken into account in the crater chronology. The "Nestingphoto technique" (Basaltic Volcanism Study Project, 1981) is not recommended in counting small craters, either. Despite the warning given by Basaltic Volcanism Study Project (1981), use of small craters for detailed dating appears to be widely accepted (e.g., Greeley et al., 1993; Neukum and Ivanov, 1994; Hartmann et al., 1999, Hartmann and Berman, 2000). Unless new evidence for the primary production hypothesis is found, we should use only large craters in the crater chronology.

\subsection{Examination of the secondary crater hypothesis}

In Subsection 3.5, we conclude that the secondary crater hypothesis is the most likely, but a few problems remain. First, there are several outlying points in Fig. 11. Among those, high $\alpha$ values of AS15-0284, 0296, and other nearby photographs can be explained by a superposition of the secondary craters from Diophantus crater $\left(27.6^{\circ} \mathrm{N}\right.$ and $34.3^{\circ} \mathrm{W}$, 18-km diameter, Fig. 2) (Taylor, 1982). In Fig. 13, we show the $\alpha$ values of the panoramic photographs within 10 crater diameters from Diophantus crater. According to the geologic map by Wilhelms et al. (1987), AS15-0288 and 0292 are covered by the ejecta blankets from Diophantus crater. Therefore two low $\alpha$ values adjacent to Diophantus crater are plausible. Otherwise, the $\alpha$ value decrease with inverse distance as Fig. 11. Similarly, the high value of $\alpha$ in the photograph AS15-0328 occurs because the area is partially covered by a ray from the Aristarchus crater (Moore, 1965) (Fig. 2) and includes numerous clusters of secondary craters. Because rays are composed of diffuse patches and filamen-

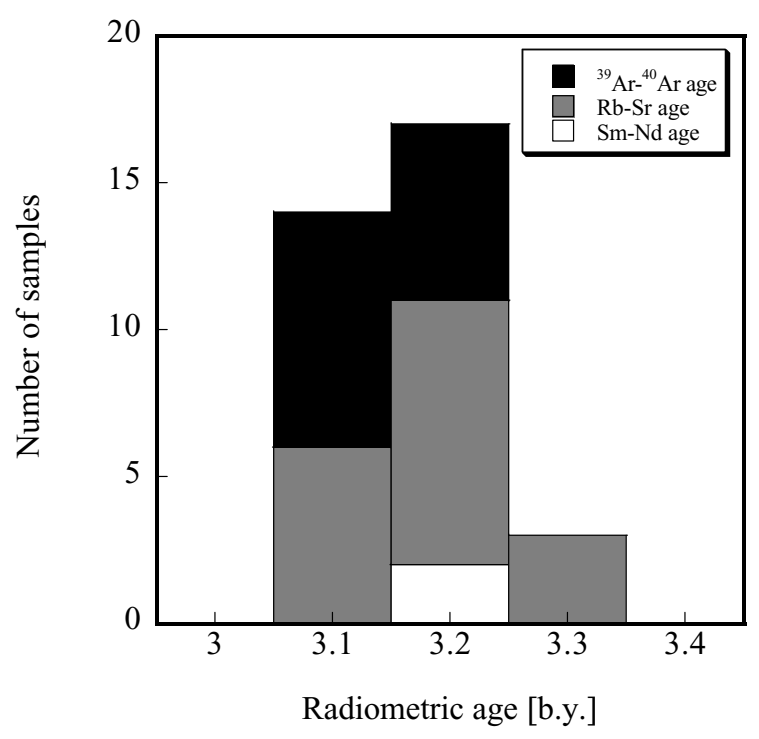

Fig. 12. A histogram of radiometric ages of Apollo 12 samples. Black, gray, and white boxes indicate ${ }^{39} \mathrm{Ar}-{ }^{40} \mathrm{Ar}$ ages, $\mathrm{Rb}-\mathrm{Sr}$ ages, and $\mathrm{Sm}-\mathrm{Nd}$ ages, respectively (Basaltic Volcanism Study Project, 1981, Table 7.3.1).

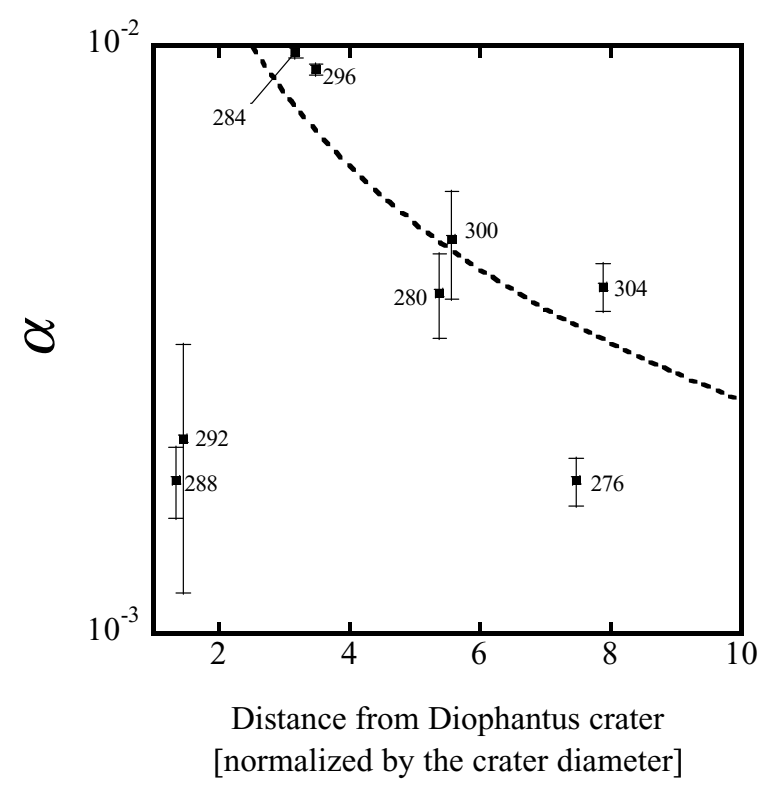

Fig. 13. A variation of $\alpha$ with distance from Diophantus crater. Dashed line is 25 (normalized distance) $^{-1}$, and numbers next to symbols indicate photograph numbers in Tables 1 and 2 . The distance is normalized by the crater diameter $(18 \mathrm{~km})$.

tary streaks, the influence of the rays complicates the interpretation of Fig. 11. For other outlying points in Fig. 11, no particular inference has been made.

Second, it is unknown why only certain large primary craters are associated with secondary craters. In Fig. 2, we can find many craters as large as Aristarchus and Diophantus craters. However, the variation of $\alpha$ in Fig. 2 is not significantly affected by other large craters. In particular, the panoramic photographs in Fig. 2 lie between 5 and 16 crater diameters from Copernicus crater $\left(9.7^{\circ} \mathrm{N}\right.$ and $20.0^{\circ} \mathrm{W}$, 93-km diameter) (Taylor, 1982), while no systematic variation of $\alpha$ is found with the distance from Copernicus craters. 
Thus our results suggest that only particular craters, such as Aristarchus and Diophantus craters in this study, form a number of secondary craters sufficient to influence the sizefrequency distribution in the surrounding area. This interpretation may explain the conflict of our argument with that of Neukum et al. (1975), who have demonstrated that the sizefrequency distribution of small craters in Mare Serenitatis is little dependent on a distance from Bessel crater and therefore have rejected the secondary crater hypothesis.

Figures 11 and 13 imply that the secondary craters and the ejecta blanket play important roles on the size-frequency distribution of small craters. However, neither their roles nor a mechanism to produce the secondary craters have been fully understood yet (e.g., Chapman and McKinnon, 1986). Advances in experimental studies of hyper-velocity impact (e.g., Gault and Wedekind, 1978; Yamamoto and Nakamura, 1997; Yamamoto, 2002) are necessary. As well, comparative tests in different regions, using high-resolution images that are expected from future lunar missions (Mizutani, 1995; Sasaki et al., 1999), are important.

\section{Conclusions}

Most of the crater size-frequency distributions on surfaces from Imbrian to Copernican ages of the moon reveal the steep-slope segment for diameters smaller than a few $\mathrm{km}$. The endogenic crater hypothesis cannot account for the steep slope of the crater size-frequency distributions on ejecta blankets of young Tycho and Copernicus craters. At the same time, the crater size-frequency distribution has little to do with basalt thickness, topography, or Bouguer gravity anomaly. Therefore it is unlikely that the physical property of subsurface materials influences the steep slope segment of the crater size-frequency distribution. The regional variation of the crater size-frequency distributions in Mare Imbrium and Oceanus Procellarum appears to have no correlation with the geologic classification, thus allowing rejection of the primary production hypothesis. We note that craters smaller than a few km should not be adopted for age determination. Finally regional variations of the size-frequency distributions reveal a close relation with a distance from a local large crater. Isolated secondary craters are the likely cause of the steep slope segment, although the reason why only a small number of craters form numerous secondary craters is unknown.

Needless to say, the area studied in this work is limited in both space and geologic ages. Therefore it is difficult to rule out completely any hypotheses. However, our results do indicate that creation of the small craters is more complex than previously thought. New high-resolution images from future lunar explorations and experimental studies on cratering mechanisms may yield new insights.

Acknowledgments. The Lunar Orbiter and Apollo photographs were processed at and provided by the National Space Science Data Center. Some of the Lunar Orbiter photographs were processed at and provided by the Regional Planetary Image Facility in the Institute of Space and Astronautical Science. The lunar gravity model JGL100J1 and topography model GLTM-2 were supplied by Geophysics Subnode of NASA's Planetary Data System (PDS) via the World Wide Web at: http://pds-geophys.wustl.edu/pds/. We gratefully acknowledge Jennifer A. Grier and an anonymous reviewer for critical and thoughtful comments. We also thank Patrick J. McGovern for his comments to the revised manuscript. This research was supported by the Ministry of Education of Japan under the grants-in-aid for Encouragement of Young Scientist (08740364, 09740382, and 12740265)

\section{References}

Alexander, E. C., Jr., A. Bates, M. R. Coscio, Jr., J. C. Dragon, V. R. Murthy, R. O. Peping, and T. R. Venkatesan, K/Ar dating of lunar soils II, Proc. Lunar Sci. Conf. 7th, 625-648, 1976.

Alexander, E. C., Jr., M. R. Coscio, Jr., J. C. Dragon, R. O. Peping, and K. Saito, K/Ar dating of lunar soils III: Comparison of ${ }^{39} \mathrm{Ar}-{ }^{40} \mathrm{Ar}$ and conventional techniques; 12032 and the age of Copernicus, Proc. Lunar Sci. Conf. 8th, 2725-2740, 1977.

Basaltic Volcanism Study Project, Basaltic Volcanism on the Terrestrial Planets, 1286 pp., Pergamon, New York, 1981.

Bogard, D. D., D. H. Garrison, D. S. McKay, and S. J. Wentworth, The age of Copernicus: New evidence for $800 \pm 15$ million years (abstract), Lunar Planet. Sci., 23, 133-134, 1992.

Budney, J. C. and P. G. Lucey, Basalt thickness in Mare Humorum: The crater excavation method, J. Geophys. Res., 103, 16855-16870, 1998.

Chapman, C. R. and W. B. McKinnon, Cratering of planetary satellites, in Satellites, edited by J. A. Burns and M. S. Matthews, pp. 492-580, Arizona University Press, Tucson, 1986.

Chapman, C. R., J. A. Mosher, and G. Simmons, Lunar cratering and erosion from Orbiter 5 photographs, J. Geophy. Res., 75, 1445-1466, 1970.

Chapman, C. R., J. C. Aubele, W. J. Roberts, and J. A. Cutts, Sub-kilometer lunar craters: Origins, ages, processes of degradation, and implications for mare basalt petrogenesis (abstract), Lunar Planet. Sci., 10, 190-191, 1979.

Chapman, C. R., J. Veverka, M. J. S. Belton, G. Neukum, and D. Morrison, Cratering on Gaspra, Icarus, 120, 231-245, 1996.

Crater Analysis Techniques Working Group, Standard techniques for presentation and analysis of crater size-frequency data, Icarus, 37, 467-474, 1979.

DeHon, R. A., Thickness of the western mare basalts, Proc. Lunar Planet. Sci. Conf. 10th, 2935-2955, 1979.

DeHon, R. A. and J. D. Waskom, Geologic structure of the eastern mare basins, Proc. Lunar Sci. Conf. 7th, 2729-2746, 1976.

Drozd, R. J., C. M. Hohenberg, C. J. Morgan, and C. E. Ralston, Cosmic ray exposure history at the Apollo 16 and other lunar sites: lunar surface dynamics, Geochim. Cosmochim. Acta, 38, 1625-1642, 1974.

Elphic, R. C., D. J. Lawrence, W. C. Feldman, B. L. Barraclough, S. Mauris, A. B. Binder, and P. G. Lucey, Lunar Fe and Ti abundances: Composition of Lunar Prospector and Clementine data, Science, 281, 1493-1496, 1998.

Feldman, W. C., B. L. Barraclough, S. Mauris, R. C. Elphic, D. J. Lawrence, D. R. Thomsen, and A. B. Binder, Major compositonal units of the Moon: The Lunar Prospector thermal and fast neutrons, Science, 281, 1489 1493, 1998a.

Feldman, W. C., S. Mauris, A. B. Binder, B. L. Barraclough, R. C. Elphic, and D. J. Lawrence, Fluxes of fast and epithermal neutrons from Lunar Prospector: Evidence for water ice at the lunar pole, Science, 281, 14961500,1998 b.

Gault, D. E., Saturation and equilibrium conditions for impact cratering on the lunar surface: Criteria and implications, Radio Sci., 5, 273-291, 1970

Gault, D. E. and J. A. Wedekind, Experimental studies of oblique impact, Proc. Lunar Planet. Sci. Conf. 9th, 3843-3875, 1978.

Gillis, J. J. and P. D. Spudis, Geology of the Smythii and Marginis region of the Moon: Using integrated remotely sensed data, Science, 105, 4217 4233, 2000.

Greeley, R., S. D. Kadel, D. A. Williams, L. R. Gaddis, J. W. Head, A. S. McEwen, S. Murchie, E. Nagel, G. Neukum, C. M. Pieters, J. M Sunshine, R. Wagner, and M. J. S. Belton, Galileo observation of lunar maria and related deposits, J. Geophys. Res., 98, 17183-17206, 1993.

Guinness, E. A. and R. E. Arvidson, On the constancy of the lunar cratering flux over the past $3.3 \times 10^{9} \mathrm{yr}$, Proc. Lunar Sci. Conf. 8th, 3475-3494, 1977.

Halekas, J. S., D. L. Mitchell, R. P. Lin, S. Frey, L. L. Hood, M. H. Acũna, and A. B. Binder, Mapping of crustal magnetic anomalies on the lunar near side by the Lunar Prospector electron reflectometer, J. Geophys. Res., 106, 27841-27852, 2001

Hartmann, W. K. and D. C. Berman, Elysium Planitia lava flows: Crater 
count choronology and geological implications, J. Geophys. Res., 105, 15011-15025, 2000.

Hartmann, W. K. and R. W. Gaskel, Planetary cratering 2: Studies of saturation equilibrium, Meteorit. Planet. Sci., 32, 109-121, 1997.

Hartmann, W. K., M. Malin, A. McEwen, M. Carr, L. Soderblom, P. Thomas, E. Danielson, P. James, and J. Veverka, Evidence for recent volcanism on Mars from crater counts, Nature, 397, 586-589, 1999.

Head, J. W., J. B. Adams, T. B. McCord, C. M. Pieters, and S. H. Zisk, Regional stratigraphy and geologic history of Mare Crisium, in Mare crisium, the view from Luna 24: proceedings of the Conference on Luna 24, Houston, Texas, December 1-3, 1977/compiled by Lunar and Planetary Institute (Geochimica et Cosmochimica Acta. suppl. 9), pp. 43-74, Pergamon, New York, 1978.

Hiesinger, H., J. W. Head, U. Wolf, and G. Neukum, Lunar mare basalts in Oceanus Procellarum: Initial results on age and composition (abstract), Lunar Planet. Sci. (CD-ROM), 31, \#1278, 2000a.

Hiesinger, H., R. Jaumann, G. Neukum, and J. W. Head, Ages of mare basalts on the lunar nearside, J. Geophys. Res., 105, 29239-29275, 2000 b.

Konopliv, A. S. and D. N. Yuan, Lunar Prospector 100th degree gravity model development (abstract), Lunar Planet. Sci. (CD-ROM), 30, \#1067, 1999.

Konopliv, A. S., A. B. Binder, L. L. Hood, A. B. Kucinskas, W. L. Sjogren, and J. G. Williams, Improved gravity field of the moon from Lunar Prospector, Science, 281, 1476-1480, 1998.

Kuiper, G. P., R. G. Strom, and R. S. Le Poole, Interpretation of the Ranger records, in Ranger VIII and IX. part II. Experimenters' Analyses and Interpretation, Jet Propulsion Lab. Tech. Rep., 32-248, 1966.

Lawrence, D. J., W. C. Feldman, B. L. Barraclough, A. B. Binder, R. C. Elphic, S. Mauris, and D. R. Thomsen, Global elemental maps of the Moon: The Lunar Prospector gamma-ray spectrometer, Science, 281, 1484-1489, 1998.

Lucchita, B. K., Crater clusters and light mantle at the Apollo 17 site: A result of secondary impact from Tycho, Icarus, 30, 80-96, 1977.

McEwen, A. S., J. M. Moore, and E. M. Shoemaker, The Phanerozoic impact cratering rate: Evidence from the farside of the Moon, J. Geophys. Res., 102, 9231-9242, 1997.

Melosh, H. J., Impact Cratering: A Geologic Process, 245 pp., Oxford University Press, New York, 1989.

Mizutani, H., Lunar interior exploration by Japanese Lunar penetrator mission, Lunar-A, J. Phys. Earth, 43, 657-670, 1995.

Moore, H. J., Geologic map of the Aristarchus region of the Moon: USGS Map1-465, scale 1:1,000.000, 1965.

Neukum, G. and B. A. Ivanov, Crater size distributions and impact probabilities on Earth from lunar, terrestrial-planet, and asteroid cratering data, in Hazards Due to Comets and Asteroids, edited by T. Gehrels, pp. 359-416, Univ. of Arizona Press, Tucson, 1994.

Neukum, G. and B. König, Dating of individual lunar craters, Proc. Lunar Sci. Conf. 7th, 2867-2881, 1976.

Neukum, G. and D. U. Wise, Mars: A standard crater curve and possible new time scale, Science, 194, 1381-1387, 1976.

Neukum, G., B. König, and J. Arkani-Hamed, A study of lunar impact crater size-distributions, The Moon, 12, 201-229, 1975.

Pickering, G., J. M. Bull, and D. J. Sanderson, Sampling power-law distributions, Tectonophys., 248, 1-20, 1995.

Pieters, C. M., Mare basalt types on the front side of the moon: A summary of spectral reflectance data, Proc. Lunar Planet. Sci. Conf. 9th, 28252849, 1978.

Pieters, C. M., J. W. Head, T. B. McCord, J. B. Adams, and S. H. Zisk, Geochemical and geological units of Mare Humorum: Definition using remote sensing and lunar sample information, Proc. Lunar Sci. Conf. 6th, 2689-2710, 1975.

Pieters, C. M., J. W. Head, L. Gaddis, B. Jolliff, and M. Duke, Rock types of South Pole-Aitken basin and extent of basaltic volcanism, J. Geophys. Res., 106, 28001-28022, 2001.

Press, W. H., B. P. Flannery, S. A. Teukolsky, and W. T. Vetterling, Numerical Recipes in C, 735 pp., Cambridge Univ. Press, Cambridge, 1988.

Rabinowitz, D., E. Bowell, E. Shoemaker, and K. Muinonen, The population of Earth-crossing asteroids, in Hazards Due to Comets and Asteroids, edited by T. Gehrels, pp. 285-314, Univ. of Arizona Press, Tucson, 1994.

Rajmon, D. and P. Spudis, Mixing of the mare regolith: A Clementine test (abstract), Lunar Planet. Sci. (CD-ROM), 31, \#1372, 2001.

Sasaki, S., Y. Iijima, K. Tanaka, M. Kato, M. Hashimoto, H. Mizutani, K. Tsuruda, and Y. Takizawa, Scientific research in the SELENE mission, paper IAF-99-Q.4.04, 50th International Astronautical Congress, Amsterdam, 4-8 October, 1999.

Schultz, P., R. Greeley, and D. Gault, Degradation of small mare surface features, Proc. Lunar Sci. Conf. 7th, 985-1003, 1976.

Schultz, P., R. Greeley, and D. Gault, Interpreting statistics of small craters, Proc. Lunar Sci. Conf. 8th, 3539-3564, 1977.

Shoemaker, E. M., Preliminary analysis of fine structure of the lunar surface in Mare Cognitum, in Ranger 7, part 2, Experimenters' Analyses and Interpretations, JPL, Technical Report 32-700, 75-132, 1965.

Silver, L. T., U-Th-Pb isotope systems in Apollo 11 and 12 regolithic materials and a possible age for the Copernican impact, Eos Trans. $A G U$, 52, 534, 1971.

Smith, D. E., M. T. Zuber, G. A. Neumann, and F. G. Lemoine, Topography of the Moon from the Clementine lidar, J. Geophys. Res., 102, 15911611, 1997.

Staid, M. I. and C. M. Pieters, Mineralogy of the last lunar basalts: Results from Clementine, J. Geophys. Res., 105, 27887-27900, 2001.

Strom, R. G., S. K. Croft, and N. G. Barlow, The Martian impact cratering record, in Mars, edited by H. H. Kieffer, B. M. Jakosky, C. W. Snyder, and M. S. Matthews, pp. 383-423, Arizona University Press, Tucson, 1992.

Taylor, S. R., Planetary Science: A Lunar Perspective, 481 pp., Lunar and Planetary Institute, Houston, 1982.

Veverka, J., P. C. Thomas, M. Robinson, S. Murchie, C. Chapman, M. Bell, A. Harch, W. J. Merline, J. F. Bell, B. Bussey, B. Carcich, A. Cheng, B. Clark, D. Domingue, D. Dunham, R. Farquhar, M. J. Gaffey, E. Hawkins, N. Izenberg, J. Joseph, R. Kirk, H. Li, P. Lucey, M. Malin, L. McFadden, J. K. Miller, W. M. Owen, C. Peterson, L. Prockter, J. Warren, D. Wellnitz, B. G. Williams, and D. K. Yeomans, Imaging of small-scale features on 433 Eros from NEAR: Evidence for a complex regolith, Science, 292, 484-488, 2001.

Weitz, C. M. and J. W. Head, Spectral properties of the Marius Hills volcanic complex and implications for the formation of lunar domes and cones, $J$. Geophys. Res., 104, 18933-18956, 1999.

Wieczorek, M. A. and R. J. Phillips, Potential anomalies on a sphere: Applications to the thickness of the lunar crust, J. Geophys. Res., 103, 1715-1724, 1998.

Whitford-Stark, J. L. and J. W. Head, Stratigraphy of Oceanus Procellarum basalts: Sources and styles of emplacement, J. Geophys. Res., 85, 65796609, 1980.

Wilhelms, D., V. Oberbeck, and H. Aggarwal, Size-frequency distribution of primary and secondary lunar impact craters, Proc. Lunar Sci. Conf. 9th, 3735-3762, 1978.

Wilhelms, D., J. McCauley, and N. Trask, The Geologic History of the Moon, 302 pp., USGS Professional Paper 1348, 1987.

Wolfe, E. W., B. K. Lucchitta, V. S. Reed, G. E. Ulrich, and A. G. Sanchez, Geology of the Taurus-Littrow valley floor, Proc. Lunar Sci. Conf. 6th, 2463-2482, 1975.

Yamamoto, S., Measurement of impact ejecta from regolith targets in oblique impacts, Icarus, 158, 87-97, 2002.

Yamamoto, S. and A. M. Nakamura, Velocity measurements of impact ejecta from regolith targets, Icarus, 128, 160-170, 1997.

Yingst, R. A. and J. W. Head, Volumes of lunar lava ponds in South PoleAitken and Orientale basins: Implications for eruption conditions, transport mechanism, and magma source regions, J. Geophys. Res., 102, 10909-10931, 1997.

Yingst, R. A. and J. W. Head, Geology of mare deposits in South PoleAitken basin as seen by Clementine UV/VIS data, J. Geophys. Res., 104, 18957-18979, 1999.

Young, R. A., Mare crater size-frequency distributions: Implications for relative surface ages and regolith development, Proc. Lunar Sci. Conf. 6th, 2645-2662, 1975.

Young, R. A., The lunar impact flux, radiometric age correlation, and dating of specific lunar features, Proc. Lunar Sci. Conf. 8th, 3457-3473, 1977.

N. Namiki (e-mail: nori@geo.kyushu-u.ac.jp) and C. Honda 